\title{
Redistribution, power sharing and inequality concern
}

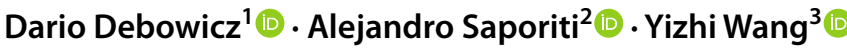

Received: 30 December 2017 / Accepted: 27 January 2021 / Published online: 10 March 2021

(c) The Author(s) 2021

\begin{abstract}
We analyze a political competition model of redistributive policies. We provide an equilibrium existence result and a full characterization of the net transfers to the different income groups. We also derive several testable predictions about the way in which the net group transfers and the after-tax Gini coefficient vary with the main parameters of the model. In accordance with the theory, the empirical evidence from a sample of developed and developing democracies supports a highly statistically significant association between: (i) the net group transfer and the gap between the population and the group mean initial income, and (ii) the net group transfer (and resp., the Gini coefficient) and power sharing disproportionality. In addition, the data also provide some empirical evidence confirming a significant relationship between the net transfers to the poor (and resp., the Gini) and the concern of the political parties with income inequality.
\end{abstract}

\footnotetext{
We warmly thank comments and suggestions from three anonymous referees, the associate editor Maggie Penn, and David Blackaby, Jennifer Golan, Minh Le, Antonio Nicoló, Don Webber, and participants from several conferences, including the 2016 Annual Conference of the Society for the Advancement of Economic Theory, the 2017 Annual Meetings of the Midwest Political Science Association, the Association for Public Economic Theory, and the European Economic Association, and the 2018 Annual Conference of the Royal Economic Society. Additional material for this article, containing several theoretical extensions, alternative econometric specifications, and summary statistics, is available in an online appendix at the corresponding author's personal web-site https:// sites.google.com/site/adsaporiti/research.
}

Alejandro Saporiti

alejandro.saporiti@manchester.ac.uk

Dario Debowicz

D.J.Debowicz@swansea.ac.uk

Yizhi Wang

yizhi.wang@tju.edu.cn

1 Swansea University, Swansea, UK

2 University of Manchester, Manchester, UK

3 Tianjin University, Tianjin, China 


\section{Introduction}

Since the mid twenty century an increasingly important activity of government in western democracies consists in redistributing income among different socio-economic groups. Quite often, this activity is not only motivated by the egalitarian goal of reducing income disparities among the citizens, but also by the tactical objectives of the political actors competing in the elections. In this paper, we study several determinants of redistributive policies, emphasising in particular the role of political power sharing, inequality concern, and partisanship. In addition, we confront our predictions to the data using a panel of developed and developing democracies.

Following recent research on social preferences and redistribution, pioneered by Alesina and Angeletos (2005a, b), ${ }^{1}$ we first modify the canonical model of redistributive politics due to Lindbeck and Weibull (1987) to allow voters to express a concern not just about their own well-being (e.g., disposable income), but also about the well-being of other members of society. This is consistent with data from laboratory experiments and neuro-imaging studies, which show that people are to some extent willing to sacrifice personal gains and share resources with others to mitigate economic inequalities.

In our model, the other-regarding concern enter into the voters' and the parties' preferences over redistributive policies as a concern with egalitarianism, i.e., a dislike of unequal outcomes per se. ${ }^{2}$ This notion of social preferences matches closely the data used in the empirical part, which suggest consistently with Alesina and Giuliano (2010) that poorer groups of individuals posses a larger disutility from income inequality. It is worth noting that, in contrast with the inequity aversion concept of Fehr and Schmidt (1999), which expresses envy and altruism and is selfcentered, ${ }^{3}$ our idea of social preferences is rooted in Arrow's (1963) tradition. That is, it is based on a "public-value" notion, as is referred to by Corneo and Gruner (2002), in the sense that individuals' attitude towards income redistribution reflects some ideal or principle of social justice about how resources ought to be distributed in society.

Besides introducing inequality concern into the utility function, we also extend the redistribution model of Lindbeck and Weibull (1987) to accommodate a continuum of power sharing rules, ranging from purely proportional representation to winner-take-all. This is motivated by the fact that in modern democracies, politics is not "all or nothing", but most often it requires consensus and compromise among multiple policymakers (Powell 2000; Franzese 2010; Lijphart 2012). For the results

\footnotetext{
1 We discuss in greater detail the literature related to our paper in Sect. 5.

2 Experimental and neural evidence of egalitarian motives in humans strongly support the role of the anterior insula of the human brain (often associated with negative emotions such as pain and distress) in promoting egalitarian behavior (Dawes et al. 2007 and 2012).

${ }^{3}$ By self-centerness we mean that fair-minded people in the inequity aversion sense is influenced by the comparison between their own payoffs and that of a reference group, but not by inequality per se, or by the differences among the payoffs of other individuals. Interestingly, experimental evidence seems to indicate that the opposite might happen in simple distribution games, where people seem to consider also differences among others in their utility functions (Engelmann and Strobel 2004).
} 
of the paper, the amount of policymaking power shared by fair-minded political actors turns out to be crucial for shaping not only the intensity of electoral competition, but also the equilibrium policy.

Following the modelling strategy of Saporiti (2014), Matakos et al. (2015), and Herrera et al. (2016), we represent power sharing in our framework with the help of a contest success function. This function is meant to reflect in a reduced-form the institutions of representation, governance, and policymaking (such as, separation of powers, the electoral system, forms of government, agenda-setting and veto powers, amendment procedures, etc.) that shape the mechanism that transforms the votes of the parties into the decision-making power or "influence" over the implemented policy. ${ }^{4}$ In our case, it specifically determines the post-election power of the political parties as a function of their relative electoral strengths, i.e., in relation to their ratio of votes. The implemented policy is then defined as a compromise between the electoral proposals, each weighted by the party's corresponding share of policymaking power. ${ }^{5}$

The main results of the paper are as follows. First, we prove that, under fairly general conditions, our redistributive election game has a unique pure-strategy Nash equilibrium. The proof rests on standard existence results for strategic games with a continuum of pure strategies. To guarantee the strict quasi-concavity of the conditional payoff functions, which are continuous over the strategy space, we impose a sufficient condition that bears similarities with Lindbeck and Weibull's (1987).

To elaborate, in our model each party's payoff function consists of two terms. The first term captures the concern of the party members with income inequality, and it is strictly concave in the party's own strategy. The second term expresses the interest of the professional politicians in policymaking power. This term is an increasing transformation of the party's vote share function, and it does not need to be concave. It depends on the distribution of the partisan biases insight each voter group, the relative individual welfare associated with the redistributive policies of the parties, and the disproportionality with which political power is shared after the election.

The condition we establish to ensure equilibrium existence imposes ipso facto two restrictions on the second term of each party's conditional payoff function. On the one hand, it constraints the disproportionality of power sharing taking into consideration the shape of the vote share function. On the other hand, it demands that the (logarithmic) rate at which the percentage of votes of each party varies as result of changes in the relative welfare of the groups be limited by the overall concavity

\footnotetext{
${ }^{4}$ Influenced by the empirical part, along the paper we employ the terms power sharing and electoral rules interchangeably and without making a distinction between them. However, as Herrera et al. (2016) points out, the former should be viewed in the theory as a much broader concept, representing not (like electoral rules) simply the mapping from votes into seat shares in the legislature, but the relationship between the electoral outcomes and the parties' direct influence over the policymaking process.

5 This assumption allows to abstract from the specificities of the (extensive-form) bargaining game that determines the implemented policy. Luckily, as Franzese (2010) points out, under complete information in any of these bargaining games the resulting equilibrium policy is a weighted-average combination of the policymakers' (or parties' in our case) most-preferred policies (platforms). Furthermore, this convex combination can be rationalized as the solution of a Nash bargaining process, where the optima of each of the players is weighted by its relative bargaining strength (Franzese 2010).
} 
of the voters' utility function. This latter part guarantees that the party's vote share is concave, but it is stronger than Lindbeck and Weibull's (1987) condition, since inequality concern relates in a non-trivial way the margin vote share associated to each income group with the net transfers received by the other groups.

Second, to understand the nature of the pure-strategy equilibrium, we characterize the net transfers to the groups using the first-order conditions of each party's constrained optimization problem. We show that both parties select the same taxand-transfer policy, which can be divided into two parts. The first part coincides with the optimal policy of a purely egalitarian party, and it is given by the difference or gap between the population and the group mean initial income. The second part represents the amount of tactical redistribution across income groups carried out for electoral purposes, and it depends on the interplay of three main factors: (i) the (relative) partisan independence of the poor, (ii) parties' and voters' inequality concern, and (iii) the electoral rule disproportionality.

Third, we derive from our equilibrium characterization a number of testable predictions that guide the empirical work. Among them, our analysis shows that the net transfers to all groups rise with the income gaps. Likewise, the gap between the partisan independence of the poor and the average across all income groups increases the transfers to the poor and reduces income inequality. We also find that inequality concern curbs electoral redistribution and inequality, transferring resources from the middle class and the rich to the poorer segment of society. Interestingly, an effect in the opposite direction on the net group transfers is driven by power sharing disproportionality.

With regard to the after-tax income inequality, we prove that the Gini index after redistribution increases as policymaking power gets more concentrated in the majority winning party. The latter as well as the effect of power sharing over the net transfers take place if and only if parties are fair-minded, in which case the intensity of the electoral competition (determined by power sharing) affects parties' willingness to trade off equity for votes. By contrast, if parties maximize simply the expected vote shares, targeted spending to the swing voter groups is not affected by the power sharing regime.

Finally, fourth, we confront the above predictions to the data using an unbalanced panel (depending on data availability) of developed and developing countries. ${ }^{6}$ Our paper adds in that regard to both, the empirical literature on the probabilistic voting model of income redistribution, and the empirical analysis of income inequality under different electoral rules. To start, we build a panel of countries and years based on information provided by the Luxembourg Income Study (LIS), from which we get the group transfers, their disposable incomes, and the Gini, and by a series of socio-economic and political datasets, from which we construct the other main variables of the model.

To elaborate, we use the European Social Survey to gather information about the extent to which voters consider that it is "important that people are treated equally and have equal opportunities”, which approximates our concept of voters' inequality

\footnotetext{
${ }^{6}$ See Table 7 at the end of the paper for details about the observations informing the regressions.
} 
concern. This database also informs about the voters' partisan alignment, which we employ to estimate the partisan independence within the income groups. On the other hand, to measure power sharing, we rely on the index of electoral rule disproportionality due to Taagepera (1986), which fits well with our theoretical concept. ${ }^{7}$ To construct the index, data on the total number of voters and parliamentary seats and the mean electoral district magnitude are obtained from various sources, including the Manifesto Project of Volkens et al. (2015) and Carey and Hix's (2011) dataset. $^{8}$

We then carry out a series of regressions, accounting for country-specific, timeinvariant fixed effects (FE) when the sample size allows, and conducting pooled ordinary least squares (OLS) otherwise. As happens with other studies in the field, the empirical evidence does not validate the well-known Meltzer and Richard's (1981) hypothesis by which progressive income redistribution is positively linked to the gap between the mean and the median of the pre-tax income distribution. In contrast, and in line with the theoretical results derived in this work, it does offer support for a highly statistically significant association between (i) the net group transfers and the income gaps, at 1\% significance level, and under both OLS and FE, and (ii) the after-tax Gini coefficient and the electoral rule disproportionality, at $1 \%$ significance and under OLS.

Consistent with our theory, the data also show a statistically significant association between the net group transfers and the power sharing index. This is confirmed at $1 \%$ significance level for the middle-class and the rich under OLS, and at $5 \%$ for the poor group under both OLS and FE. In addition, we find some evidence of a negative and significant (at 10\%) association between the Gini and party inequality concern, particularly when controlling for voters' inequality concern and partisan independence.

The net transfers to the poor group are also found under OLS to be empirically associated (at $1 \%$ significance) with party inequality concern. However, regressions accounting for voters' inequality concern and partisan independence do not lend almost any empirical support to their association with the net transfers and the Gini coefficient. Although these results are obtained from relatively smaller datasets, they are in line with other results in the empirical literature on targeted spending, which find weak evidence in validating the swing voter argument. In our case, the results are also consistent with the fact that fair-minded parties engage less on tactical spending.

The rest of the paper is organised as follows. We set up the model in Sect. 2. The theoretical results are in Sect. 3. Section 4 describes the hypotheses to be tested, the data, and the main empirical results. Section 5 concludes the paper discussing the key findings and the related literature. For expositional convenience, Appendix A

\footnotetext{
${ }^{7}$ The online appendix also considers the Gallegher's (1991) index, which is another well-known measure of an electoral system's disproportionality. The results reported below and summarized in Tables 8 and 9, Appendix B, are similar under the two specifications.

${ }^{8}$ For the sake of conciseness, the reader is referred to Sect. 4 for further details about the data and the definition of the Taagepera's (1986) index.
} 
collects the proofs; and Appendix B displays the countries and the years informing the regressions, and a brief overview of the results under the alternative econometric specifications considered in this work. Finally, the online appendix offers summary statistics, a more detailed exposition of the regressions carried out, and several theoretical extensions.

\section{The model}

\subsection{Voters}

Consider a continuum $N$ of voters divided into three disjoined groups: the rich $(R)$, the middle class $(M)$, and the poor $(P)$. Let $n_{i} \in(0,1)$ denote the size of group $i \in N$, with $\sum_{i \in N} n_{i}=1$, and let $\sigma_{i}=n_{i} /\left(1-n_{i}\right)$ be group $i$ 's relative size in relation to the other groups. Suppose $e_{i}>0$ denotes the initial income of every voter of group $i \in N$. Assume the income distribution is skewed to the right, with the mean income $e=\sum n_{i} e_{i}$ greater than the median $\bar{e}$, and $e_{R}>e>\bar{e}=e_{M}>e_{P}$.

In order to represent voters' preferences for redistribution, let $\mathbf{z}=\left(z_{i}\right)_{i \in N} \in Z$ be an arbitrary income distribution, with $Z=\left\{\mathbf{z} \in \mathbb{R}_{+}^{N} \mid \sum_{i \in N} n_{i} z_{i}=\sum_{i \in N} n_{i} e_{i}\right\}$ denoting the set of all such allocations. The utility of a voter in group $i$ over $Z$ is given by

$$
u_{i}(\mathbf{z})=z_{i}-\alpha_{i} \sum_{j \in N} n_{j}\left(z_{j}-z\right)^{2}
$$

where $\alpha_{i} \in \mathbb{R}_{+}, z_{i}$ (resp., $z_{j}$ ) denotes voter $i$ 's (resp., j's) income under the distribution $\mathbf{z} \in Z$, and $z=\sum_{j \in N} n_{j} z_{j}$ is the population mean income.

The preferences shown in equation (1) are additively separable in the voter's concern with his own well-being and his concern with the others'. The first term of the right-hand side denotes voter $i$ 's selfish utility over his income $z_{i}$. The second term, i.e., $-\alpha_{i} \sum_{j \in N} n_{j}\left(z_{j}-z\right)^{2}$, measures voter $i$ 's intrinsic concern with inequality. To be more specific, voter $i$ 's inequality concern is represented by the weighted sum of the distances between each group's average income and the population mean, with the weights given by the group sizes and $\alpha_{i}$. Following the data of Sect. 4.1, we assume that $\alpha_{P}>\alpha_{M}>\alpha_{R}$, reflecting the fact that poorer groups display a greater disutility from income inequality.

\subsection{Political process}

To eliminate any unwanted inequality associated with the initial allocation of resources, there is a political process that redistributes income across groups through a tax-and-transfer policy. Let $x_{i} \in \mathbb{R}$ denote the net transfer to voters of group $i \in N$. A balanced-budget redistributive policy is a vector $\mathbf{x}=\left(x_{i}\right)_{i \in N} \in \mathbb{R}^{N}$ such that $\sum_{i \in N} n_{i} x_{i}=0$ and $x_{i} \geq-e_{i}$ for all $i \in N$. We further restrict the set of all such policies, denoted by $X$, to guarantee non-income-sorting. This ensures that the ranking 
of disposable incomes $y_{i}=e_{i}+x_{i}$ after redistribution preserves the ordering of the initial incomes of the groups, that is, $y_{R} \geq y_{M} \geq y_{P}{ }^{9}$

There are two political parties, indexed by $C \in\{A, B\}$, that compete in an election proposing simultaneously and independently a redistributive policy $\mathbf{x}^{C} \in X{ }^{10}$ Like in the Lindbeck-Weibull model, each voter has a partisan bias toward the parties, which is unrelated to the current policy. This preference is fixed in the shortterm, and may depend on prior political experience, attributes of the candidates, ideology, etc. Before the election, the political parties are unsure about the partisan preferences of the electorate. More precisely, they view voter $i$ 's partisan bias $\theta_{i}$ as being drawn from a twice continuously differentiable distribution function $F_{i}(\cdot)$ over $\mathbb{R}$, with a density $f_{i}(\cdot)$ that takes a value at zero (neutral bias) of $f_{i}(0)=\phi_{i}>0$.

Following data about partisan independence and the income groups taken from the European Social Survey and discussed in Sect. 4, we assume that $\phi_{M}>\phi>\phi_{P}>\phi_{R}$, where $\phi=\sum n_{i} \phi_{i}$. These conditions on the densities imply that the middle class is the "swing voter group" in our model, with the highest proportion of partisan independent voters, followed by the poor, and the rich. ${ }^{11}$ In addition, the second inequality, that is, $\phi>\phi_{P}$, rules out the less compelling case where all voters have the same after-tax equilibrium income. Finally, to prevent any group to be fully expropriated and be left with a non-positive after-tax income, we assume that $\phi_{P}>\phi-2 \alpha_{\phi} e$, where $\alpha_{\phi}=\sum_{i \in N} n_{i} \phi_{i} \alpha_{i}$ is an average across groups reflecting independent voters' inequality concern.

At the election, each voter votes sincerely for the party's proposal that offers higher utility. ${ }^{12}$ Specifically, a voter of group $i$ votes for party $A$ if $u_{i}\left(\mathbf{y}^{A}\right) \geq u_{i}\left(\mathbf{y}^{B}\right)+\theta_{i}$, where $\mathbf{y}^{C}=\left(y_{i}^{C}\right)_{i \in N}$, with $y_{i}^{C}=e_{i}+x_{i}^{C}$ representing group $i$ 's after-tax income under the policy of party $C$. Given that for every group $i \in N$, the initial income $e_{i}$ is held fixed throughout the analysis, in the sequel we simply denote $u_{i}(\cdot)$ as a function of $\mathbf{x}^{C}$. Therefore, the probability that a voter in group $i$ votes for party $A$ given the platforms $\mathbf{x}^{A}$ and $\mathbf{x}^{B}$ is $\operatorname{Prob}\left(\theta_{i} \leq u_{i}\left(\mathbf{x}^{A}\right)-u_{i}\left(\mathbf{x}^{B}\right)\right)=F_{i}\left(u_{i}\left(\mathbf{x}^{A}\right)-u_{i}\left(\mathbf{x}^{B}\right)\right)$. As a result, the expected vote share of party $A$, denoted by $v^{A}$, is given by $v^{A}\left(\mathbf{x}^{A}, \mathbf{x}^{B}\right)=\sum_{i \in N} n_{i} F_{i}\left(u_{i}\left(\mathbf{x}^{A}\right)-u_{i}\left(\mathbf{x}^{B}\right)\right)$. Assuming that there is no abstention, party $B$ 's vote share is simply $v^{B}=1-v^{A}$.

After the election, the winning party and the opposition jointly determine the tax-and-transfer policy $\mathbf{x} \in X$ in accord with their platforms $\mathbf{x}^{C}$ and their relative political strengths $\rho^{C}$. To be precise, we assume that $\mathbf{x}=\rho^{A} \mathbf{x}^{A}+\rho^{B} \mathbf{x}^{B}$, where $\rho^{C}=\Phi\left(v^{C}\right)$ denotes party $C^{\prime}$ 's power share ("influence") at the policymaking process

\footnotetext{
${ }^{9}$ Like in the Lindbeck-Weibull model, under income-sorting the ranking of the groups after redistribution changes in equilibrium in such a way that the rich becomes the lowest income group. This is not very realistic, since non-rich voters do not seem to possess in western democracies the political power to carry out such level of expropriation. Despite this, when income-sorting is permitted, the online appendix shows that the main qualitative properties of the equilibrium transfers are similar.

${ }^{10}$ Hereafter, it is understood that the index $-C$ denotes $B$ if $C=A$, and $A$ if $C=B$.

11 Persson and Tabellini (1999) also argue in favor of thinking of the group with the highest density of partisan independent voters as consisting of middle class voters.

12 This entails no loss of generality because the probability of being pivotal at the election is zero given the continuum of voters.
} 
as an increasing function $\Phi:[0,1] \rightarrow[0,1]$ of party $C$ 's vote share $v^{C}$, with the usual requirement that $\rho^{B}=1-\rho^{A}$. The influence over policy $\rho^{C}$ exerted by each party can be interpreted as its probability of determining alone policy $\mathbf{x} \in X$, which is expected to be increasing in the party's vote share.

Regarding the specific functional form of the power sharing rule, we follow an string of the literature that sees party influence over policy as being determined by the relative electoral strengths of the parties, represented here by the ratio of votes. To be precise, we assume that the power sharing rule $\rho^{C}$ is given by

$$
\rho^{C}=\frac{1}{1+\left(\frac{1-v^{C}}{v^{C}}\right)^{\eta}},
$$

where the parameter $\eta \geq 1$ represents the proportionality of the electoral rule. ${ }^{13}$

Simple algebraic manipulation shows that (2) implies that $\rho^{C} / \rho^{-C}=\left(v^{C} / v^{-C}\right)^{\eta}$, which is Theil's (1969) well-known hypothesis about how vote shares translate into seat shares in a legislature. When $\eta=1$, the expression above represents the purely proportional representation system, where the influence of each party coincides with its vote share. As the parameter $\eta$ rises above 1, the electoral rule gets more disproportionate and biased in favour of the majority winning party. ${ }^{14}$ In the limit, as $\eta$ approaches infinity, (2) captures the winner-take-all system where the party holding more votes controls all branches of government and sets policy unilaterally.

To complete the model, we introduce the parties' payoff functions, $\Pi^{C}(\cdot)$, which are a combination of the interests of (i) the politicians and party leaders, who seek power to influence policy, and (ii) other party members and supporters, who care to a certain extent about the well-being of other individuals in society. Formally, the payoff of party $C$ is defined as $\Pi^{C}\left(\mathbf{x}^{A}, \mathbf{x}^{B}\right)=(1-\gamma) \cdot \rho^{C}-\gamma \frac{1}{2} \cdot \sum_{i \in N} n_{i}\left(y_{i}^{C}-e\right)^{2}$, where $\gamma \in[0,1]$ denotes the parties' inequality concern. ${ }^{15}$ When $\gamma=0$, parties maximize their expected vote shares. At the other extreme when $\gamma=1$, they seek to achieve an egalitarian distribution of income. In between these cases, parties compete motivated by both power and equity.

\footnotetext{
${ }_{13}$ An alternative to equation (2) would be to see parties' power shares as a function of the margin of victory (or electoral mandate), instead of the ratio of votes. The qualitative results of the paper are robust to this alternative specification, since the equilibrium characterization under the "margin of victory" power sharing rule only suffers minor changes in comparison with that derived under (2). Details are omitted for the sake of brevity, but they are available in the online appendix.

${ }^{14}$ For instance, when $\eta=3$, the seat allocation follows the "cube law", which is seen as approximating the distortions created in favour of the winner party in the first-past-the-post elections.

15 Alternatively, $\gamma$ could be seen as a cost parameter for the party associated to campaigning on policies perceived as "socially insensible" (i.e., the cost of building the image of being a "nasty party" that only cares about the privileged few and not the many, as the British Conservative Prime Minister, Theresa May, put it in her 2002 party conference speech). The online appendix offers further results for the case where this cost might be different for the parties (i.e., where $\gamma_{A} \neq \gamma_{B}$ ).
} 


\subsection{Timing}

Let $\mathcal{G}=\left(X, \Pi^{C}\right)_{C=A, B}$ denote the redistributive election game sketched above. The timing of this game is as follows. First, parties $A$ and $B$ propose simultaneously and non-cooperatively redistributive policies $x^{A}$ and $x^{B}$, respectively. At this stage, parties know the initial income of the groups, voters' preferences over the income distribution, and the group-specific cumulative distributions of the partisan bias, but not yet their realized values. Second, the actual values of $\theta_{i}$ are realized and all uncertainty is resolved. Third, voters cast their vote for one of the parties. Fourth, the vote and the power shares are determined and, together with the parties' proposals, they determine the tax-and-transfer policy. Finally, fifth, parties and voters receive their respective payoffs.

\section{Equilibrium analisis}

\subsection{Existence}

We begin the equilibrium analysis showing that under fairly general conditions, the redistributive election game has a unique equilibrium in pure strategies. To do that, for each group $i \in N$, let the index $\left(\sum_{j \in N} \xi_{i j}(\mathbf{x})\right)^{-1}$ be a measure of the overall concavity of the utility function $u_{i}(\cdot)$ at $\mathbf{x} \in X$, where $\xi_{i j}(\mathbf{x})=-\frac{\left[\partial u_{i}(\mathbf{x}) / \partial x_{j}\right]^{2}}{\partial^{2} u_{i}(\mathbf{x}) / \partial x_{j} \partial x_{j}}$. Fix $C$ and $\mathbf{x}^{-C} \in X$, and define for each group $i \in N$ and for each party $C^{\prime}$ 's proposal $\mathbf{x}^{C} \in X$, the utility differential $t_{i}\left(\mathbf{x}^{C}\right)=u_{i}\left(\mathbf{x}^{C}\right)-u_{i}\left(\mathbf{x}^{-C}\right)$. Let $\kappa_{i}\left(\mathbf{x}^{C}\right)=\frac{f_{i}^{\prime}\left(t_{i}\left(\mathbf{x}^{C}\right)\right)}{f_{i}\left(t_{i}\left(\mathbf{x}^{C}\right)\right)}$ be the (logarithmic) rate at which the rate of change of party $C^{\prime}$ s vote share $v^{C}\left(\cdot, \mathbf{x}^{-C}\right)$ varies within group $i \in N$ in response to changes in $t_{i}\left(\mathbf{x}^{C}\right) .{ }^{16}$ A sufficient condition for $v^{C}\left(\cdot, \mathbf{x}^{-C}\right)$ to be concave on $X$ is as follows:

Condition $\mathbb{C}_{1}$ : For all $i \in N$, and all $\mathbf{x}^{C} \in X, \kappa_{i}\left(\mathbf{x}^{C}\right) \leq\left(\sum_{j \in N} \xi_{i j}\left(\mathbf{x}^{C}\right)\right)^{-1}$.

This condition is fulfilled in a number of meaningful cases, including the uniform distribution and the doubly exponential distribution (logit) case considered by Lindbeck and Weibull (1987), the latter when the overall concavity is greater than one. As a passing remark, notice that in the Lindbeck-Weibull model the right-hand side of Condition $\mathbb{C}_{1}$ reduces to $\left(\xi_{i i}\left(\mathbf{x}^{C}\right)\right)^{-1}$. The reason is the cross-derivatives of the vote share $v^{C}\left(\cdot, \mathbf{x}^{-C}\right)$ with respect to party $C$ 's net transfers are all null, which simplifies greatly its Hessian matrix. Instead, in our case due to the inequality concern, the marginal increase in the percentage of votes that party $C$ obtains by changing group $i$ 's transfers $x_{i}^{C}$ varies with the transfers $x_{j}^{C}$ to group $j \neq i$.

Although the condition above is enough to ensure that each party's vote share is concave given the policy of the other party, this is not sufficient for equilibrium

\footnotetext{
${ }^{16}$ For instance, in the uniform case this ratio is equal to zero, meaning that changes in the utility differential affect the vote share of each political party at a constant rate.
} 
existence. The reason is the parties' payoff functions involve the power shares $\rho^{C}$, which are an increasing transformation $\Phi$ of $v^{C}$. Therefore, in addition to $\mathbb{C}_{1}$, a restriction on $\Phi$ is needed to preserve the concavity of $\Phi\left(v^{C}\left(\cdot, \mathbf{x}^{-C}\right)\right)$ on $X$. To do that, fix as before party $C$ and the policy of the other party $\mathbf{x}^{-C} \in X$. For each group $i, j \in N$ and every policy $\mathbf{x}^{C} \in X$, denote $\delta_{i j}\left(\mathbf{x}^{C}\right)=\frac{\partial^{2} v^{C}\left(\mathbf{x}^{C}, \mathbf{x}^{C}\right) / \partial x_{i}^{C} \partial x_{j}^{C}}{\partial v^{C}\left(\mathbf{x}^{C}, \mathbf{x}^{-C}\right) / \partial x_{i}^{C} \cdot \partial v^{C}\left(\mathbf{x}^{C}, \mathbf{x}^{C}\right) / \partial x_{j}^{C}}$, and let $\delta\left(v^{C}\right)=\frac{\Phi^{\prime \prime}\left(v^{C}\right)}{\Phi^{\prime}\left(v^{C}\right)}$ for each $v^{C} \in[0,1]$. Next, define for each $\mathbf{x}^{C} \in X$ the $3 \times 3$ matrix $\Delta\left(\mathbf{x}^{C}\right)=\left(\delta_{i j}\left(\mathbf{x}^{C}\right)\right)_{i, j \in N}$, where $\Delta^{k}\left(\mathbf{x}^{C}\right), k=1,2,3$, represents the determinant of the $k$-th leading principal minor of $\Delta$ at $\mathbf{x}^{C}$. Finally, given any square matrix $M=\left(m_{i j}\right)$, denote by $M_{[i, u]}$ the matrix obtained from $M$ by replacing in each column of the $i$-th row the entry scalar $u$.

Our next condition can be formally stated as follows:

Condition $\mathbb{C}_{2}$ : For all $\mathbf{x}^{C} \in X$ and each $k,(-1)^{k+1} \Delta^{k}\left(\mathbf{x}^{C}\right) \leq(-1)^{k} \sum_{j \leq k} \Delta_{[j, \delta]}^{k}\left(\mathbf{x}^{C}\right)$.

In practice, depending on the different values adopted by the main parameters of the model, (particularly, on $\alpha_{i}$ and $F_{i}(\cdot)$ ), Condition $\mathbb{C}_{2}$ establishes an upper bound on the disproportionality parameter $\eta$ below which the power sharing function exhibited in equation (2) satisfies concavity. ${ }^{17}$ Therefore, with these two conditions $\mathbb{C}_{1}$ and $\mathbb{C}_{2}$ in place, we are now ready to state our result on equilibrium existence.

Proposition 1 If conditions $\mathbb{C}_{1}$ and $\mathbb{C}_{2}$ hold for each party $C$, then the redistributive election game $\mathcal{G}$ has a unique Nash equilibrium in pure strategies.

For expositional convenience, the proof of the previous proposition is displayed in Appendix A, as is the proof of any other result of the paper. Our formal argument rests on the standard existence results for strategic games with a continuum of pure strategies. To guarantee the quasi-concavity of the conditional payoff functions, we impose a sufficient condition (i.e., $\mathbb{C}_{1}$ and $\mathbb{C}_{2}$ ) that generalizes Lindbeck and Weibull's (1987), but it is stronger due to the presence of social preferences and the power sharing mechanism.

\subsection{Characterization}

Having proved the existence of a unique Nash equilibrium in pure strategies, we move next to the characterization of the corresponding tax-and-transfer policies, which allow later to derive several testable predictions that guide our empirical analysis.

\footnotetext{
17 By being an increasing and concave transformation of the party's vote share, under condition $\mathbb{C}_{1}$ the power share function is always concave between half and one. The restriction on $\eta$ is necessary to preserve concavity below half, that is, for the range of values of the vote share over which $\Phi$ is increasing but convex. Otherwise, if $\eta$ were not constrained, it could be the case that the political parties increase their power sharing by reducing their percentage of votes in the election, which would eliminate the trade-off investigated in this paper between equity and votes.
} 
Proposition 2 Let $\left(\mathbf{x}^{A}, \mathbf{x}^{B}\right) \in X \times X$ denote the pure-strategy Nash equilibrium of the redistributive election game $\mathcal{G}$. For all $i \in N, x_{i}^{A}=x_{i}^{B}$, where

$$
x_{i}^{C}=\underbrace{\left(e-e_{i}\right)}_{E R}+\underbrace{\beta_{i}\left(\phi-\phi_{P}\right)}_{T R}, C=A, B,
$$

with $\beta_{P}=-\frac{(1-\gamma) \eta}{(1-\gamma) 2 \eta \alpha_{\phi}+\gamma}<0$ and $\beta_{M}=\beta_{R}=\frac{(1-\gamma) \eta \sigma_{P}}{(1-\gamma) 2 \eta \alpha_{\phi}+\gamma}>0$.

The characterization given in Proposition 2 points out that despite the electoral system (that is, proportional representation, winner-take-all, or a system in between), the usual centripetal forces of electoral competition lead the political parties to converge to a similar redistributive policy. ${ }^{18}$ More importantly, it also shows that the tax-and-transfer policy to which the parties converge consists of two parts:

- A first part, called egalitarian redistribution (ER), which coincides with the policy chosen by a political party concerned only with inequality, and it is equal to the gap between the population and the group mean initial income; and

- A second part, called tactical redistribution (TR), which captures the income transfers carried out by the politicians across the voter groups to increase their electoral support; and that depends on three main factors: (i) the partisan independence gap of the poor, measured by the difference between the density of swing voters in that group and the average density in society, (ii) the proportionality of the electoral rule, and (iii) parties' and voters' inequality concern.

The assumptions on the income distribution and on the group densities imply that the equilibrium transfers to the middle class are positive. For the other groups, the sign is indeterminate because ER and TR work in opposite directions. By playing with the magnitudes of these two, it could happen that either the middle class and the poor (resp., rich) benefit from income redistribution at the expense of the rich (resp., poor); or that the middle class is the only group benefiting from redistributive politics, a result known in the literature as Director's law.

From the utilitarian viewpoint, the equilibrium displayed in Proposition 2 can be rationalized as the policy outcome obtained by maximizing a social welfare function that weights voters' utilities according with the group sizes, the ex-ante distribution of partisan preferences, the inequality concern parameters, and the electoral rule disproportionality. To be more precise:

\footnotetext{
18 As a note of caution, notice that our equilibrium result doesn't produce the convergence to the median voter's most-preferred policy, as is the case in the Downsian framework. It does preserve, however, the principle of minimum differentiation of spatial competition, which is a common feature shared by other election games with two symmetric parties and full commitment to the campaign proposals. The online appendix shows an example with asymmetric motivations (asymmetric party inequality concern) where the parties do not converge to the same policy. This is also a feature shared by other asymmetric election games, even within the Downsian model (see, for instance, Drouvelis et al. 2014).
} 
Corollary 1 If $\mathbf{x}^{C} \in X$ denotes party $C$ 's equilibrium policy at the election game $\mathcal{G}$, then $\mathbf{x}^{C}=\arg \max _{\mathbf{x} \in X} \sum_{i \in N} d_{i} u_{i}(\mathbf{x})$, where $d_{i}=(1-\gamma) \eta n_{i} \phi_{i}+\gamma \frac{n_{i}}{2 \sum_{i \in N} n_{i} \alpha_{i}}$.

Besides revealing that the egalitarian part only varies (rises) with the income gaps, Proposition 2 offers some insight about how tactical redistribution is affected by the other parameters of the model. Corollaries 2-3 below collect these results. ${ }^{19}$ To start, notice that an increase in $\phi_{P}$ raises the transfers to the poor, as is indicated by (2.A), because they become more responsive to policy and their votes are easier to swing. Due to the non-income-sorting restrictions and the balanced-budget condition, both binding at the equilibrium, a greater $\phi_{P}$ decreases simultaneously (and in the same magnitude) the total transfers received by the non-poor.

Corollary 2 Let $\mathbf{x}^{C} \in X$ denote party C's equilibrium policy at the redistributive election game $\mathcal{G}$. For all $i \in N, \frac{\partial x_{M}^{C}}{\partial \phi_{i}}=\frac{\partial x_{R}^{C}}{\partial \phi_{i}}=-\sigma_{P} \frac{\partial x_{P}^{C}}{\partial \phi_{i}}$, and

(2.A) $\frac{\partial x_{P}^{C}}{\partial \phi_{P}}=\beta_{P} \cdot \frac{\left(n_{P}-1\right) \gamma+(1-\gamma) 2 \eta\left[\left(n_{P}-1\right) \alpha_{\phi}-n_{P} \alpha_{P}\left(\phi-\phi_{P}\right)\right]}{(1-\gamma) 2 \eta \alpha_{\phi}+\gamma}>0$,

(2.B) $\frac{\partial x_{i}^{C}}{\partial \phi_{i}}=\beta_{i} \cdot \frac{n_{i} \gamma+(1-\gamma) 2 \eta n_{i}\left[\alpha_{\phi}-\alpha_{i}\left(\phi-\phi_{P}\right)\right]}{(1-\gamma) 2 \eta \alpha_{\phi}+\gamma}$, with $i=M, R$.

As is shown in (2.B), the effect of a change in $\phi_{M}$ (resp., $\phi_{R}$ ) over $x_{i}^{C}$ is indeterminate, meaning that in contrast with Lindbeck and Weibull (1987), electorally motivated transfers do not necessarily rise in all groups with the percentage of swing voters. ${ }^{20}$ On the one hand, a greater $\phi_{M}$ (resp., $\phi_{R}$ ) raises the average density of swing voters across groups, reducing the electoral appeal of the poor vis-à-vis the middle class. Given that the non-sorting constraint of the middle class and the rich is binding at the equilibrium, this reduces also the appeal of the poor vis-à-vis the rich. Thus, the first effect (through the rise of the partisan independence gap of the poor) is positive for $x_{M}^{C}$ and $x_{R}^{C}$, and negative for $x_{P}^{C}$. On the other hand, an increase in $\phi_{M}$ (resp., $\phi_{R}$ ) also increases $\beta_{P}$ and reduces the coefficients $\beta_{M}$ and $\beta_{R}$. This works in the direction opposite to the first effect, capturing how the inequality concern and power sharing interact with the partisan preferences. Thus, the total effect of a change of $\phi_{M}\left(\right.$ resp., $\phi_{R}$ ) over $x_{i}^{C}$ is ambiguous.

The second set of comparative statics results points out that the effect of (either citizens' or parties') inequality concern over TR-transfers is negative for the middle class and the rich, who benefit from this type of redistribution, and positive for the poor (see (3.A) and (3.B) below). This means that social preferences curb to some extent money transfers across income groups motivated by elections. As was pointed out before, ER-transfers are not directly affected by inequality concern.

\footnotetext{
${ }^{19}$ In what follows, we assume that $\gamma \neq 1$, since otherwise group transfers consist only of egalitarian redistribution and they are invariant to changes in the parameters investigated.

20 This result is, however, reestablished when income-sorting is permitted. For more details, see the online appendix at the corresponding author's personal web-site.
} 
Corollary 3 Let $\mathbf{x}^{C} \in X$ denote party $C$ 's equilibrium policy at the redistributive election game $\mathcal{G}$. For all $i \in N$, and all $t=\alpha_{i}, \gamma, \eta$, sign $\left(\frac{\partial x_{i}^{C}}{\partial t}\right)=\operatorname{sign}\left(\frac{\partial \beta_{i}}{\partial t}\right)$, and
(3.A) $\frac{\partial \beta_{R}}{\partial \alpha_{i}}=\frac{\partial \beta_{M}}{\partial \alpha_{i}}=-\sigma_{P} \frac{\partial \beta_{P}}{\partial \alpha_{i}}=-\frac{2(1-\gamma)^{2} \eta^{2} \sigma_{P} n_{i} \phi_{i}}{\left[(1-\gamma) 2 \eta \alpha_{\phi}+\gamma\right]^{2}}<0$,
(3.B) $\frac{\partial \beta_{R}}{\partial \gamma}=\frac{\partial \beta_{M}}{\partial \gamma}=-\sigma_{P} \frac{\partial \beta_{P}}{\partial \gamma}=-\frac{\eta \sigma_{P}}{\left[(1-\gamma) 2 \eta \alpha_{\phi}+\gamma\right]^{2}}<0$,
(3.C) $\frac{\partial \beta_{R}}{\partial \eta}=\frac{\partial \beta_{M}}{\partial \eta}=-\sigma_{P} \frac{\partial \beta_{P}}{\partial \eta}=\frac{(1-\gamma) \gamma \sigma_{P}}{\left[(1-\gamma) 2 \eta \alpha_{\phi}+\gamma\right]^{2}}>0$.

Finally, the effect of the power sharing parameter on TR-transfers is positive for the high density group, that is, the middle class; and due to the non-income-sorting (resp., balanced-budget) constraint, it is also positive (resp., negative) for the rich (resp., poor). This captures that a political system that assigns policy influence more disproportionately among political parties rises the importance of winning a majority at the election, and thereby the interest of the parties in the swing voter group. This result resembles that derived in Persson and Tabellini (1999), according to which majoritarian elections make electoral competition stiffer, and that implies more targeted redistribution towards the politically influential middle class. In particular, (3.C) implies that tactical redistribution toward the middle class and the rich (resp., poor) is at the lowest (resp., highest) level under proportional representation, and increases (resp., decreases) smoothly as the power sharing system gets more disproportionate.

The closed-form expression of the tax-and-transfer policy allows also to investigate the effect of the parameters of the model on income inequality after redistribution. To do that, we follow a usual method of estimating the Gini coefficient when data is grouped into classes. This consists in approximating the Lorenz curve by a series of straight lines joining the known points, and then calculating the relevant area as a series of trapezia and triangles. The resulting estimation, denoted $\hat{G}$, can be written as

$$
\hat{G}=1-\sum_{i \in N^{\prime}} n_{i}\left(Y_{i}+Y_{j}\right), \quad j=i-1,
$$

where $N^{\prime}$ is a rearrangement of $N$ in the order of increasing after-tax incomes, $Y_{\ell}$ denotes the percentage of cumulative income up until group $\ell$ (with $Y_{0}=0$ ), and $j=i-1$ refers to the group immediate before group $i$ in terms of its income share (Fuller 1979).

Corollary 4 The groups' after-tax equilibrium incomes $y_{i}=e+\beta_{i}\left(\phi-\phi_{P}\right), i \in N$, determine an estimate of the Gini coefficient equal to $\hat{G}=n_{P} \beta_{P}\left(\phi_{P}-\phi\right) e^{-1}$. Thus,
(4.A) $\frac{\partial \hat{G}}{\partial \alpha_{i}}=n_{P}\left(\phi_{P}-\phi\right) e^{-1} \frac{\partial \beta_{P}}{\partial \alpha_{i}}<0, i \in N$,
(4.B) $\frac{\partial \hat{G}}{\partial \gamma}=n_{P}\left(\phi_{P}-\phi\right) e^{-1} \frac{\partial \beta_{P}}{\partial \gamma}<0$,
(4.C) $\frac{\partial \hat{G}}{\partial \eta}=n_{P}\left(\phi_{P}-\phi\right) e^{-1} \frac{\partial \beta_{P}}{\partial \eta}>0$, 
(4.D) $\frac{\partial \hat{G}}{\partial \phi_{i}}=n_{P} e^{-1} \beta_{P}\left[\frac{\partial \phi_{P}}{\partial \phi_{i}}-n_{i}+\left(\phi-\phi_{P}\right) \frac{(1-\gamma) 2 \eta n_{i} \alpha_{i}}{(1-\gamma) 2 \eta \alpha_{\phi}+\gamma}\right], i \in N$.

The first two items of Corollary 4, that is, (4.A) and (4.B), confirm that income inequality decreases as society exhibits a greater inequality concern. More interestingly, (4.C) reveals that the Gini estimate is positively related with the disproportionately of the power sharing rule, which amount to say that income inequality rises as policymaking power gets more concentrated in the majority winning party. Finally, the swing voter effect over the Gini, given by (4.D), is negative for the poor, since the term in square brackets is positive and $\beta_{P}<0$. This is pretty intuitive, since a larger density of independent voters within the poor induces more transfers to the group at the expense of both the rich and the middle class. For these two groups, the sign of (4.D) depends on the parameters of the model and it is therefore indeterminate.

\section{Empirical evidence}

The main purpose of this section is to assess empirically the equilibrium predictions derived above. To be more specific, we aim to test the following list of hypotheses, conveniently summarized in Table 1 .

Hypothesis 1 The net transfers to all income groups increase with the gap between the population and the group average pre-tax income.

Hypothesis 2 The net transfers to the poor (resp., non-poor):

(2.A) rise (resp., decrease) with the percentage of independent voters among the poor;

(2.B) increase (resp., decrease) with voters' and parties' inequality concern;

(2.C) decrease (resp., increase) with power sharing disproportionality.

Hypothesis 3 The Gini coefficient associated with the distribution of after-tax disposable incomes:

(3.A) decreases with the percentage of independent voters among the poor;

(3.B) decreases with voters' and parties' inequality concern;

(3.C) rises with the disproportionality of the power sharing rule.

\subsection{Data}

The data employed to carry out the econometric tests is as follows. ${ }^{21}$ On the one hand, to examine Hypotheses 1 and 2, we use as regressands the real net public

${ }^{21}$ For brevity, the control variables used in the regressions are described in the online appendix. 
transfers received by the three income groups, defined according to micro-data and procedure standards provided by LIS, and taking exchange rates and deflators from the Penn World Table (PWT) of Feenstra et al. (2015). On the other hand, to assess Hypothesis 3, the dependent variable is the most widely used measure of income inequality, namely, the Gini index, taken from the Key Figures of LIS, which provides high quality data.

Given the ability of governments to manipulate different components of the public transfers and taxes, we consider three empirical approximations to the group transfers. First, we consider a broad measure, given by the social security transfers minus the sum of the social security contributions and the income taxes. Second, we consider a narrow definition, given by the public assistance transfers minus the income taxes. Finally, third, we consider a moderate version of the transfers, given by the social security transfers minus the income taxes and the old-age (public insurance and universal) pensions. This moderate definition results in a very small sample of country-year observations, so we leave it out of the analysis.

The individual market income is derived from the disposable household income by subtracting the net transfers, in their broad and narrow definitions. The market income, disposable income, and the public transfers are all expressed in equivalent terms, following the LIS procedure of dividing each nominal quantity by the square root of the household size. All figures are expressed in thousands of 2005 USD per year, using (LCU/USD) exchange rates and (US) price levels from PWT. We define the poor applying the widely used series of EU-SILC risk-of-poverty lines. In the data presented below, a poor household is one with equivalized market income below $70 \%$ of the country- and year-specific median income. The individuals in the top decile of equivalized incomes are classified as rich. The remaining individuals constitute the middle class. ${ }^{22}$ For the three groups, we aggregate the market incomes, disposable incomes, and the public transfers in each country and year using the population weights present in LIS.

To test the hypotheses involving the electoral rule disproportionality, we employ the Taagepera's (1986) index, which is built by dividing the logarithm of the total number of voters by the logarithm of the total number of parliamentary seats, and powering the result to the inverse of the mean electoral district magnitude. This index runs from 1 (proportional representation) to infinity (winner-take-all), with higher values indicating that policymaking power is more disproportionately allocated among the political parties, just as the theory of Sect. 2 postulates. To construct the index, data on the total number of votes for each election and country is collected from IDEA. ${ }^{23}$ On the other hand, the total number of seats (and respectively, the electoral district magnitudes) are gathered from the Manifesto Project Dataset (MPDS) of Volkens et al. (2015) (and respectively, from Carey and Hix's (2011) data set).

\footnotetext{
22 In the online appendix, we offer sensitivity analysis on the group definitions following all the other risk-of-poverty lines used by EU-SILC.

23 International Institute for Democracy and Electoral Assistance (IDEA) Database, (multiple countries; 1945-2014). Stockholm: IDEA. Web address: http://www.idea.int/db.
} 
Table 1 Effects of the parameters over the net transfers and the Gini

\begin{tabular}{llllll}
\hline & \multicolumn{3}{l}{ Net transfers $\left(x_{i}\right)$} & Gini \\
\cline { 2 - 3 } & Poor & MC & Rich & $(\hat{G})$ \\
\hline Income gap of the poor $\left(e-e_{P}\right)$ & + & & & \\
Income gap of the MC $\left(e-e_{M}\right)$ & & + & & \\
Income gap of the rich $\left(e-e_{R}\right)$ & & & + & \\
Partisan Independence of the poor $\left(\phi_{P}\right)$ & + & - & - & - \\
Inequality concern of the poor $\left(\alpha_{P}\right)$ & + & & & - \\
Inequality concern of the MC $\left(\alpha_{M}\right)$ & & - & & - \\
Inequality concern of the rich $\left(\alpha_{R}\right)$ & & & - & - \\
Party inequality concern $(\gamma)$ & + & - & - & - \\
Electoral rule disproportionality $(\eta)$ & - & + & + & + \\
\hline
\end{tabular}

The main explanatory variables in Hypotheses (2.B) and (3.B) are voters' and parties' concern with inequality. To approximate the former, we consider biannual micro-data from the European Social Survey (ESS), for the period 2002-2014 (seven rounds), where each respondent is asked the extent to which a person stating that it is "important that people are treated equally and have equal opportunities" is like him. ${ }^{24}$ Our measure of voters' concern toward inequality is generated in such a way that it focuses on respondents who have voted in the last election previous to the survey. It takes a value of 1 if the voter answers "very much like me"; 0 if she or he answers "not like me" (or "not like me at all"); and 0.25, 0.50, and 0.75, respectively, if she or he answers "a little like me", "somewhat like me", and "like me".

For the first three waves of the ESS, where incomes are classified in Euro-denominated brackets, we assume a uniform distribution inside these brackets to re-classify individuals into country- and year-specific income deciles, consistently with the classification in ESS from wave four. Once we have all individuals classified in income deciles, we assign those in the top decile to the rich group and, using the country-specific relative poverty rates from EU-SILC, we identify the poor. The middle class is determined once again as the residual of these two groups. We finally obtain our group measure of inequality concern as the weighted average, inside each income group, of the respondents' values. The results from the t-Student test suggest that inequality concern is significantly higher (at 10\% confidence level) for the poor group than for the middle class. In addition, the middle class displays higher inequality concern than the rich, even when the difference is not statistically significant under the usual significance levels.

\footnotetext{
${ }^{24}$ A strength of ESS data is that it includes responses to the same questions from people in a large number of European and associated countries, and has systematic sample weights to make the data nationally representative. This facilitates inter-country comparisons, and makes it possible to relate differences in attitudes across countries to country-specific factors.
} 
Regarding the parties' inequality concern, we build an index going from 0 to 1 based on the MPDS question at the party level (per503 Social Justice: Positive) ${ }^{25}$ This gathers information about the need for fair treatment of all people; the special protection for the underprivileged; the need for fair distribution of resources; the removal of class barriers; the end of discrimination of racial and sexual nature, etc. We normalize the data to have a minimum of zero and a maximum of 1 , and we calculate an average over the parties weighting each of them by their respective vote share in the election.

Finally, to assess Hypotheses (2.A) and (3.A), we construct a measure of partisan independence within each income group. First, we elicit each respondent's partisan bias by looking at a question in the ESS questionnaire where the subject is asked how close to the parties she or he feels. Our measure of the voter's partisan independence takes a value of 1 if she or he does not feel close to any party; 0 if she or he feels very close to a party; 0.25 if she or he feels quite close to a party; and 0.50 (and resp, 0.75) if she or he feels closer to one party than to all the others, but does not feel close to that party (and resp., at all). We obtain then our measure of group partisan independence using the same aggregation procedure applied for the voters' inequality concern.

To investigate the difference between the means of these distributions among our three income groups, we perform unpaired (two sample) t-Student tests, on samples with 155 country-year observations. The null hypothesis is that the population means related to two independent and random samples from approximately normal distributions (allowing for unequal variances) are equal. The results from the tests suggest that, while the average partisan independence of the poor and the middleclass are not statistically different, the rich group has an index of partisan independence significantly lower (at $1 \%$ significance level) than the other two groups.

Besides the definitions and the data sources described above, further details about the structure of our data are as follows. The variables provided by LIS are observed for several years and with different sparsity, as is shown in Table 7. The variables underlying both the Taagepera index and the parties' inequality concern are observed for each election, and they are assumed to be constant during the office term. The voters' values, i.e., inequality concern and partisan independence, are observed every two years, in accordance with the ESS. The rest of the variables are observed on a yearly basis. ${ }^{26}$

\footnotetext{
${ }_{25}$ In the online appendix, we present results for an alternative index of the parties' inequality concern that combines the one we present here with MPDS-per504: "Favourable mentions of need to introduce, maintain or expand any public social service or social security scheme".

${ }^{26}$ Within the control variables (described in the online appendix), schooling and the age of democracy are linearly interpolated for the years with missing data within the range of observed data points.
} 


\subsection{Empirical estimations}

Since the data in this work are grouped into clusters of countries, the estimations displayed below control for the presence of within-cluster correlated errors. ${ }^{27}$ To do that, we rely on the method proposed by Cameron and Miller (2015). This consists in estimating first the regression model with no control for within-cluster error correlation; and then in obtaining post-estimation the "cluster-robust" standard errors, which allow for correlated and heteroscedastic errors. Given the relatively small number of clusters that we have, we follow the authors' suggestion and we use t-Student critical values to base our inferences.

Apart from controlling for within-cluster correlated errors, notice that regressing the net group transfers using every parameter involved in the equilibrium characterization of Sect. 3 severely restricts the number of observations available in our sample. Thus, we proceed by regressing in the first place the net transfers on the income gaps, the parties' inequality concern, and the electoral rule disproportionality. This allows us to work with more than 100 country-year observations. The results from these regressions are displayed in Table 2. Like in the rest of the tables discussed below, the online appendix shows that most of these results are robust to several alternative specifications of the econometric model and/or definitions of the main variables employed in the regressions. ${ }^{28}$

Overall, the estimations above suggest that there exists a positive and highly statistically significant association between each group's income gap and the net transfers that the group receives, offering empirical support to Hypothesis 1. This positive association is found using not only OLS, but also FE. That is, it is present even when we ignore the between-country variability of the observed variables and we conduct the estimations exploiting only the within-country variability.

In the OLS case, Table 2 also shows that higher electoral rule disproportionality is statistically associated with greater transfers to the middle-class and the rich, and with lower transfers to the poor (Hypothesis 2.C). Regarding the corresponding FE estimations, which rely on an smaller within-country variability of the independent variable, the results have the expected sign and they are statistically significant only for the transfers to the poor. Finally, the OLS results show that higher party inequality concern is statistically associated with greater transfers to the poor, providing some evidence in favor of Hypothesis 2.B. Moreover, even when the transfers to the middle-class increase (instead of decrease) with the party inequality concern, for a given unit rise in the inequality concern, the average increase in the transfers to the poor group is much higher. ${ }^{29}$ Thus, a rise of parties' inequality concern does appear

\footnotetext{
27 When regression errors are correlated within clusters, standard errors for the estimated coefficients overstate the precision of the estimators, leading to over-accept the hypotheses under analysis.

28 The reader is referred to Appendix B for a general overview of the robustness analysis carried out and its corresponding results. A more detailed discussion is also available in the online appendix.

29 The OLS coefficients in Table 2 imply that if the parties' inequality concern rises in one unit, the transfers to the poor increase $84 \%$ (i.e., $100 \cdot\left(\frac{9.50}{5.16}-1\right)$ ) more than the transfers to the middle-class.
} 
to be associated with a smaller gap between the after-tax incomes of the non-poor and the poor group, as predicted by the theory.

When considering our narrower definition of the transfers, the regressions offer further support for Hypothesis 1, with both estimators providing positive and highly significant estimates for the effect of the income gaps on the net transfers to the groups, as is shown in Table 3. However, the support for Hypothesis 2.B vanishes; and that for Hypothesis 2.C is relatively more limited. That is, the association between the group transfers and the electoral rule disproportionality not only holds with statistical significance in the OLS case, but also the disproportionality of the rule increases the transfers to the three groups. Having said that, for a given unit rise in the electoral rule disproportionality, the average increase in the transfer to the poor is much lower than the increase in the transfer to the middle-class, which is in turn significantly lower than the transfer to the rich. ${ }^{30}$ Thus, consistent with the theory, even with a narrow measure of the net transfers, a rise of the electoral rule disproportionality is associated with a greater gap between the after-tax incomes of the non-poor and the poor group.

Next, we reexamine our hypotheses including in the regressions voters' inequality concern and partisan independence. This limits significantly the sample size and it constrains the analysis to OLS. The results provided in Table 4 confirms the empirical support for Hypotheses 1 and 2.C, though the link between the net transfers to the middle-class and the electoral rule disproportionality lacks statistical significance. In favor of Hypothesis 2.A, we do find that the partisan independence of the poor is positively associated with the net transfers to the group, but without significance. Regarding Hypothesis 2.B, voters' inequality concerns (holding their pretransfer income constant) are not significantly associated with the expected sign to the net transfers of the groups.

To complete the analysis and before considering the Gini, we look at the group transfers taking the alternative view of Meltzer and Richard (1981), by which progressive redistribution depends positively on the skew of the pre-tax income distribution. Specifically, we analyze if the net transfers to the poor and the middleclass (and resp., the rich) depends positively (and resp., negatively) on the skew of the income distribution, determined in the Key Figures of LIS by the mean to median ratio. Table 5 shows that the evidence found is rather inconsistent with this hypothesis.

To elaborate, with OLS the net transfers to the poor are decreasing rather than increasing on the mean to median ratio; and there is no statistically significant association between the skew of the distribution and the transfers to the middle-class (and, resp., the rich). With FE, the effect of the skew on the net transfers to the rich is negative and significant (as the theory predicts), but its effects on the net transfers to the poor and the middle-class are not statistically significant. Thus, both OLS and

\footnotetext{
30 The OLS coefficients in Table 3 imply that if the electoral rule disproportionality increases in one unit, then the net transfers to the poor increase $58 \%$ (i.e., $100 \cdot\left(1-\frac{0.80}{1.91}\right)$ ) less than the net transfers to the middle-class, and $70 \%$ (i.e., $100 \cdot\left(1-\frac{0.80}{2.68}\right)$ less than the net transfers to the rich.
} 
Table 2 Net transfers (full sample)

\begin{tabular}{|c|c|c|c|c|c|c|}
\hline & \multicolumn{3}{|c|}{ Least squares (OLS) } & \multicolumn{3}{|c|}{ Fixed effects (FE) } \\
\hline & Poor & $\mathrm{MC}$ & Rich & Poor & $\mathrm{MC}$ & Rich \\
\hline Income gap of the poor $\left(e-e_{P}\right)$ & $\begin{array}{l}0.51 * * * \\
(0.03)\end{array}$ & & & $\begin{array}{l}0.54 * * * \\
(0.04)\end{array}$ & & \\
\hline Income gap of the $\mathrm{MC}\left(e-e_{M}\right)$ & & $\begin{array}{l}0.94 * * * \\
(0.16)\end{array}$ & & & $\begin{array}{l}0.61 * * * \\
(0.13)\end{array}$ & \\
\hline Income gap of the rich $\left(e-e_{R}\right)$ & & & $\begin{array}{l}0.45 * * * \\
(0.04)\end{array}$ & & & $\begin{array}{l}0.39 * * * \\
(0.03)\end{array}$ \\
\hline Electoral rule disproportionality $(\eta)$ & $\begin{array}{l}-0.91^{* *} \\
(0.43)\end{array}$ & $\begin{array}{l}1.23 * * * \\
(0.38)\end{array}$ & $\begin{array}{l}3.87 * * * \\
(1.14)\end{array}$ & $\begin{array}{l}-25.39 * * \\
(10.36)\end{array}$ & $\begin{array}{l}-7.18 \\
(4.98)\end{array}$ & $\begin{array}{l}-14.21 \\
(21.75)\end{array}$ \\
\hline Party inequality concern $(\gamma)$ & $\begin{array}{l}9.50 * * * \\
(2.64)\end{array}$ & $\begin{array}{l}5.16^{* * *} \\
(1.99)\end{array}$ & $\begin{array}{l}-0.83 \\
(5.95)\end{array}$ & $\begin{array}{l}3.83 \\
(3.32)\end{array}$ & $\begin{array}{l}1.95 \\
(1.87)\end{array}$ & $\begin{array}{l}2.76 \\
(2.37)\end{array}$ \\
\hline $\bar{N}$ & 113 & 113 & 113 & 113 & 113 & 113 \\
\hline FE groups & - & - & - & 23 & 23 & 23 \\
\hline$R^{2}$ & 0.86 & 0.69 & 0.84 & 0.87 & 0.46 & 0.85 \\
\hline
\end{tabular}

Cluster-robust standard errors are provided in parentheses.

$R^{2}$ is adjusted- $R^{2}$ for OLS, and within- $R^{2}$ for FE.

OLS regressions include dummies on real per capita income (p.c.i.) identifying: (i) countries with real p.c.i. between $15 \mathrm{~K}$ and $20 \mathrm{~K}$ USD PPP 2005 , and (ii) countries with real p.c.i. above $20 \mathrm{~K}$.

FE regressions include a set of country-specific dummies

$* p<0.10 ; * * p<0.05 ; * * * p<0.01$.

Table 3 Net transfers (narrow definition \& full sample)

\begin{tabular}{|c|c|c|c|c|c|c|}
\hline & \multicolumn{3}{|c|}{ Least squares (OLS) } & \multicolumn{3}{|c|}{ Fixed effects (FE) } \\
\hline & Poor & $\mathrm{MC}$ & Rich & Poor & $\mathrm{MC}$ & Rich \\
\hline Income gap of the poor $\left(e-e_{P}\right)$ & $\begin{array}{l}0.12 * * \\
(0.05)\end{array}$ & & & $\begin{array}{l}0.14 * * * \\
(0.04)\end{array}$ & & \\
\hline Income gap of the $\mathrm{MC}\left(e-e_{M}\right)$ & & $\begin{array}{l}1.26^{*} \\
(0.70)\end{array}$ & & & $\begin{array}{l}0.99 * * * \\
(0.28)\end{array}$ & \\
\hline Income gap of the rich $\left(e-e_{R}\right)$ & & & $\begin{array}{l}0.37 * * * \\
(0.04)\end{array}$ & & & $\begin{array}{l}0.37 * * * \\
(0.03)\end{array}$ \\
\hline Electoral rule disproportionality $(\eta)$ & $\begin{array}{l}0.80 * * * \\
(0.24)\end{array}$ & $\begin{array}{l}1.91 * * \\
(0.75)\end{array}$ & $\begin{array}{l}2.68^{*} \\
(1.50)\end{array}$ & $\begin{array}{l}-5.02 \\
(5.65)\end{array}$ & $\begin{array}{l}6.91 \\
(13.39)\end{array}$ & $\begin{array}{l}-10.70 \\
(22.21)\end{array}$ \\
\hline Party inequality concern $(\gamma)$ & $\begin{array}{l}0.93 \\
(2.57)\end{array}$ & $\begin{array}{l}-3.33 \\
(4.74)\end{array}$ & $\begin{array}{l}-7.13 \\
(9.80)\end{array}$ & $\begin{array}{l}-0.91 \\
(1.65)\end{array}$ & $\begin{array}{l}-1.21 \\
(2.96)\end{array}$ & $\begin{array}{l}0.79 \\
(4.77)\end{array}$ \\
\hline$N$ & 90 & 90 & 90 & 90 & 90 & 90 \\
\hline FE groups & - & - & - & 19 & 19 & 19 \\
\hline$R^{2}$ & 0.32 & 0.43 & 0.71 & 0.47 & 0.25 & 0.83 \\
\hline
\end{tabular}

Cluster-robust standard errors are provided in parentheses.

$R^{2}$ is adjusted- $R^{2}$ for OLS, and within- $R^{2}$ for FE.

OLS regressions include dummies identifying: i) countries with real p.c.i. between $15 \mathrm{~K}$ and $20 \mathrm{~K}$ USD PPP 2005, and ii) countries with real p.c.i. above $20 \mathrm{~K}$.

FE regressions include a set of country-specific dummies

$* p<0.10 ; * * p<0.05$; *** $p<0.01$. 
Table 4 Net transfers (small sample)

\begin{tabular}{llll}
\hline & Poor & Middle class & Rich \\
\hline Income gap of the poor $\left(e-e_{P}\right)$ & $0.46^{* * *}$ & & \\
Income gap of the MC $\left(e-e_{M}\right)$ & $(0.06)$ & $0.96^{* * *}$ & $(0.26)$ \\
Income gap of the rich $\left(e-e_{R}\right)$ & & & $0.60^{* * *}$ \\
& & & $(0.06)$ \\
Partisan independence of the poor $\left(\phi_{P}\right)$ & 13.58 & $(1.74$ & 11.84 \\
& $(8.85)$ & & $(21.10)$ \\
Inequality concern of the poor $\left(\alpha_{P}\right)$ & -5.13 & & \\
& $(8.70)$ & 7.91 & \\
Inequality concern of the MC $\left(\alpha_{M}\right)$ & & $(9.63)$ & $30.99^{*}$ \\
& & & $(14.96)$ \\
Inequality concern of the rich $\left(\alpha_{R}\right)$ & & 1.21 & 11.45 \\
Party inequality concern $(\gamma)$ & 3.64 & $(8.10)$ & $(15.73)$ \\
& $(5.41)$ & 2.18 & $(1.59)$ \\
Electoral rule disproportionality $(\eta)$ & 1.11 & $(1.69)$ & 27 \\
& $(1.51)$ & 27 & 0.91 \\
\hline$N$ & 27 & 0.73 &
\end{tabular}

Cluster-robust standard errors are provided in parentheses

Regressions include dummies identifying: i) countries with real p.c.i. between $15 \mathrm{~K}$ and $20 \mathrm{~K}$ USD PPP 2005 , and ii) countries with real p.c.i. above $20 \mathrm{~K}$

$* p<0.10 ; * *: p<0.05 ; * * * p<0.01$.

Table 5 Net transfers (Meltzer-Richard's hypothesis \& full sample)

\begin{tabular}{|c|c|c|c|c|c|c|}
\hline & \multicolumn{3}{|c|}{ Least Squares (OLS) } & \multicolumn{3}{|c|}{ Fixed Effects (FE) } \\
\hline & Poor & $\mathrm{MC}$ & Rich & Poor & $\mathrm{MC}$ & Rich \\
\hline $\begin{array}{l}\text { Skew (Mean to Median } \\
\text { ratio) }\end{array}$ & $\begin{array}{l}-14.35^{* *} \\
(6.34)\end{array}$ & $\begin{array}{l}10.70 \\
(6.38)\end{array}$ & $\begin{array}{l}12.46 \\
(15.28)\end{array}$ & $\begin{array}{l}35.89 \\
(23.53)\end{array}$ & $\begin{array}{l}-11.86 \\
(9.22)\end{array}$ & $\begin{array}{l}-112.42 * * * \\
(35.62)\end{array}$ \\
\hline $\begin{array}{l}\text { Per Capita Income 15K- } \\
\text { 20K }\end{array}$ & $\begin{array}{l}4.76^{* *} \\
(1.91)\end{array}$ & $\begin{array}{l}-2.46^{*} \\
(1.39)\end{array}$ & $\begin{array}{l}-12.99 * * \\
(5.33)\end{array}$ & & & \\
\hline $\begin{array}{l}\text { Per Capita Income above } \\
20 \mathrm{~K}\end{array}$ & $\begin{array}{l}5.34 * * \\
(2.17)\end{array}$ & $\begin{array}{l}-4.93^{* * *} \\
(1.20)\end{array}$ & $\begin{array}{l}-21.32 * * * \\
(5.14)\end{array}$ & & & \\
\hline Constant & $\begin{array}{l}21.1(8.28) \\
8^{* *}\end{array}$ & $\begin{array}{l}-13.29 * * \\
(7.87)\end{array}$ & $\begin{array}{l}-20.06 \\
(20.59)\end{array}$ & $\begin{array}{l}-40.84 \\
(26.99)\end{array}$ & $\begin{array}{l}13.60 \\
(10.58)\end{array}$ & $\begin{array}{l}127.95^{* * * *} \\
(40.86)\end{array}$ \\
\hline$N$ & 120 & 120 & 120 & 120 & 120 & 120 \\
\hline FE groups & - & - & - & 27 & 27 & 27 \\
\hline$R^{2}$ & 0.12 & 0.26 & 0.26 & 0.08 & 0.05 & 0.18 \\
\hline
\end{tabular}

Cluster-robust standard errors are provided in parentheses.

$R^{2}$ is adjusted- $R^{2}$ for OLS, and within- $R^{2}$ for FE.

FE regressions include a set of country-specific dummies

$* p<0.10 ; * * p<0.05 ; * * p<0.01$. 
Table 6 Gini coefficient

Full sample

OLS

\begin{tabular}{|c|c|c|c|}
\hline Partisan independence of the poor $\left(\phi_{P}\right)$ & & & $\begin{array}{l}1.64 \\
(10.36)\end{array}$ \\
\hline Inequality concern of the poor $\left(\alpha_{P}\right)$ & & & $\begin{array}{l}30.53 * * \\
(11.20)\end{array}$ \\
\hline Inequality concern of the $\mathrm{MC}\left(\alpha_{M}\right)$ & & & $\begin{array}{l}9.73 \\
(15.07)\end{array}$ \\
\hline Inequality concern of the rich $\left(\alpha_{R}\right)$ & & & $\begin{array}{l}-26.64 * * \\
(9.69)\end{array}$ \\
\hline Party inequality concern $(\gamma)$ & $\begin{array}{l}-6.87 \\
(4.94)\end{array}$ & $\begin{array}{l}-0.92 \\
(2.76)\end{array}$ & $\begin{array}{l}-12.70^{*} \\
(6.02)\end{array}$ \\
\hline Electoral rule disproportionality $(\eta)$ & $\begin{array}{l}2.75 * * * \\
(0.81)\end{array}$ & $\begin{array}{l}26.30 \\
(28.80)\end{array}$ & $\begin{array}{l}3.63 * * \\
(1.26)\end{array}$ \\
\hline $\bar{N}$ & 171 & 171 & 30 \\
\hline FE groups & - & 26 & - \\
\hline$P^{2}$ & 0.41 & 0.22 & 0.79 \\
\hline
\end{tabular}

Cluster-robust standard errors are provided in parentheses.

$R^{2}$ is adjusted- $R^{2}$ for OLS, and within- $R^{2}$ for FE.

Regressions in columns 1 and 2 control for real GDP p.c. and its square, $\%$ of the population with completed secondary school, age of democracy, trade openness, population size, and \% of the population between 15 and 64, and over 65. Regression in column 3 controls for real GDP p.c., completed secondary school, trade openness, and population structure.

FE regressions include a set of country-specific dummies

$* p<0.10 ; * * p<0.05 ; * * * p<0.01$.

FE offer a priori evidence against progressive redistribution being simply explained by the skew of the pre-tax income distribution. ${ }^{31}$

Turning to the impact on the after-tax income inequality, subject to the controls enumerated in Table 6, the evidence from OLS regressions offers strong support for Hypothesis 3.C, suggesting a positive and highly significant association between the Gini index and power sharing disproportionality. These results are displayed in column (1) and column (3) of Table 6. In the full sample, that is, column (1), this evidence arises from 26 different countries and 171 country-year observations. The coefficient of the independent variable suggests that, other things equal, the effect of power sharing on income inequality has a sensitivity of about 0.3 points in the Gini

\footnotetext{
31 A number of reasons have been suggested to explain why the Meltzer and Richard's (1981) hypothesis has met with mixed evidence in the data. Among them, it is argued that rising inequality might allow the very rich to exert more influence on the political views of the less affluent and the politicians. Rising inequality might also lower the turnout more among the less affluent, which is sometimes referred to as disenfranchisement of the poor. As a consequence, the pivotal voter might not be the median in the income distribution, but a richer individual. Finally, the median voter argument that lies behind the Meltzer and Richard's idea only holds when politics is one-dimensional. However, elections deal with several other issues besides redistribution (e.g., religion, race, nationalism, immigration, etc.); and even redistribution is, as noted by Lindbeck and Weibull (1987), a multi-dimensional matter.
} 
index for each 0.1 point of increase in the Taagepera index. The corresponding FE estimator in column (2) also suggests a positive (and even higher) effect of power sharing on the Gini, but without statistical significance (due presumably to the low within-country variability of both, the Gini and the Taagepera indices).

As can be seen in column (3) of Table 6, including in the regression the voters' concern with inequality and the partisan independence of the poor restricts the sample to merely 30 observations. Therefore, the conclusions drawn from this regression should be taken just as preliminary evidence deserving further investigation. The estimation does not offer support to Hypothesis 3.A. However, it does provides evidence on rich voters' and parties' inequality concern be significantly associated with the after-tax income inequality (Hypothesis 3.B). In the case of the latter, which has the greater statistical significance, a movement from the lowest to the highest value of party inequality concern observed in the sample, (namely, from 0.005 for Hungary in 2005 to 0.495 for Finland in 1995), generates an estimated reduction in the Gini of about 6.2 points. The variation in the Gini also appears to be fairly well explained, with a $R^{2}$ coefficient of 0.79. Like in the other cases, the F-statistics (not tabulated) indicate that none of these models can be rejected on any conventional significance level.

\section{Discussion}

In this paper, we have reexamined the problem of income redistribution in a model of political competition with power sharing and inequality concern. We have characterized the equilibrium net transfers to the income groups and shown that they consist of two parts, called egalitarian and tactical redistribution. We have also shown how these transfers vary with their main determinants, that is, with the gap between the population and the group average pre-tax incomes, the partisan independence gap of the poor, electoral rule disproportionality, and parties' and voters' concern with inequality. In particular, the theoretical and the empirical results suggest that the net transfers to the more responsive group of voters (i.e., the middle class) and the after-tax Gini index both rise as policymaking power gets more concentrated in the majority winning party.

These results add to the literature on "targeted spending" (Cox and McCubbins 1986; Lindbeck and Weibull 1987; Dixit and Londregan 1995 and Dixit and Londregan 1996), which has been used in the study of the size and the scope of public spending, social security, regional transfers, etc. (Persson and Tabellini 2000). Our work contributes in two fronts. The theory fills a gap in the current models by analysing electoral redistribution under a large variety of power sharing arrangements and in the presence of social preferences. The empirical part adds to the previous work by looking at income redistribution among different socio-economic groups, instead of focusing on inter-governmental transfers to sub-national regions (provinces, counties, etc.), as much of the literature does.

Additionally, our empirical approach differs from other papers in that we employ survey data to construct direct measures of voters' and parties' characteristics, instead of using exit polling data or data from the past elections to approximate the proportion of swing voters in the different geographical districts (Arulampalam et al. 2009; Cox 2010; Larcinese et al. 2013). This strategy is problematic because 
voting behaviour is endogenous by assumption to electoral targeted spending, and it can therefore lead to biased estimates. We expect the endogeneity bias to be less significant in our case because the correlation of survey data with voting behaviour in recent elections isn't expected to be high.

Our research also contributes to the literature on redistribution and other-regarding preferences. Within the Meltzer and Richard's (1981) model of redistributive politics, preferences for redistribution have been studied in Galasso (2003), Alesina and Angeletos (2005a, b), Tyran and Sausgruber (2006), Dhami and al-Nowaihi (2010a, b), Luttens and Valfort (2012), and Flamand (2012). In the context of the probabilistic voting model, to our knowledge the only article that incorporates preferences for fairness is Alesina et al. (2012). The latter analyzes a dynamic extension of the Lindbeck-Weibull model with a winner-take-all election at the end of each period. The aim of the paper is to show how different perceptions of fairness of the market outcomes can lead to different steady states of redistribution and growth. Our paper complements Alesina et al. (2012) by analyzing theoretically and empirically the consequences of different distributions of policymaking power over the redistributive policies and income inequality. By being dynamic, Alesina et al.'s (2012) framework isn't appropriate for that goal due to the lack of an accepted theory about how political power sharing evolves over time.

Finally, our work also adds to the literature on redistribution and inequality under different electoral rules (namely, first-past-the-post (FPTP) and proportional representation (PR)). A central prediction is that PR favors spending on goods that benefit broad social groups, whereas FPTP favors spending on goods provided to specific subsets of voters (Persson and Tabellini 1999; Lizzeri and Persico 2001; MilesiFerretti et al. 2002; and Funk and Gathmann 2013). To our knowledge, this paper constitutes the first attempt to bring this insight into a framework with a rich variety of mixed electoral systems, which not only reflects better the reality of many democracies, but it also allows to quantify the effects of small changes in these rules over both redistribution and the Gini. ${ }^{32}$

\section{Appendix A: Theoretical Appendix}

Proof of Proporsition 1 To show that $\mathcal{G}=\left(X, \Pi^{C}\right)_{C=A, B}$ has a unique pure-strategy equilibrium, we employ Debreu-Glicksberg-Fan's existence result. First, note that the strategy space $X$ is non-empty, compact, and convex. Second, each function $\Pi^{C}\left(\mathbf{x}^{A}, \mathbf{x}^{B}\right)$ is continuous on $\left(\mathbf{x}^{A}, \mathbf{x}^{B}\right) \in X^{2}$. Thus, it remains to prove that, under conditions $\mathbb{C}_{1}$ and $\mathbb{C}_{2}$, each conditional payoff function $\Pi^{C}\left(\cdot, \mathbf{x}^{-C}\right)$ is strictly quasi-concave on $X$.

Fix any policy $\overline{\mathbf{x}}^{B} \in X$, and consider the resulting conditional payoff function $\Pi^{A}\left(\cdot, \overline{\mathbf{x}}^{B}\right)$ of party $A$. The proof for party $B$ is similar. Note that the second term of party A's conditional payoff, namely, $-\gamma \frac{1}{2} \cdot \sum_{i \in N} n_{i}\left(y_{i}^{A}-e\right)^{2}$, is strictly concave in the party's own strategy. Thus, to prove that $\Pi^{A}\left(\cdot, \overline{\mathbf{x}}^{B}\right)$ is strictly quasi-concave on $X$, it suffices to show that the power share function $\rho^{A}\left(\mathbf{x}^{A}, \overline{\mathbf{x}}^{B}\right)$ is concave in $\mathbf{x}^{A}$.

$\overline{32}$ For a comparative analysis of mixed electoral systems, see Moser and Scheiner (2004). 
Starting with party $A$ 's vote share, recall that for all $\mathbf{x}^{A} \in X$, $v^{A}\left(\mathbf{x}^{A}, \overline{\mathbf{x}}^{B}\right)=\sum_{i \in N} n_{i} v_{i}^{A}\left(\mathbf{x}^{A}, \overline{\mathbf{x}}^{B}\right)$, with $v_{i}^{A}\left(\mathbf{x}^{A}, \overline{\mathbf{x}}^{B}\right)=F_{i}\left(u_{i}\left(\mathbf{x}^{A}\right)-u_{i}\left(\overline{\mathbf{x}}^{B}\right)\right)$. Consider the Hessian matrix associated to each $v_{i}\left(\mathbf{x}^{A}, \overline{\mathbf{x}}^{B}\right)$, i.e., $H_{i}\left(\mathbf{x}^{A}\right)=\left[\frac{\partial^{2} v_{i}\left(\mathbf{x}^{A}, \overline{\mathbf{x}}^{B}\right)}{\partial x_{i}^{A} \partial x_{j}^{A}}\right]_{i, j \in N}$. Since for all $i \neq j, i, j \in N$, the second-order partial derivatives $\frac{\partial^{2} u_{i}\left(\mathbf{x}^{A}\right)}{\partial x_{i}^{A} \partial x_{j}^{A}}=0$, it is easy to show that the matrix $H_{i}\left(\mathbf{x}^{A}\right)$ is negative semi-definite on $X$ if for all $\mathbf{x}^{A} \in X$,

$$
\begin{gathered}
\frac{\partial^{2} v_{i}\left(\mathbf{x}^{A}, \overline{\mathbf{x}}^{B}\right)}{\partial x_{i}^{A} \partial x_{i}^{A}} \leq 0 \Longleftrightarrow \kappa_{i}\left(\mathbf{x}^{A}\right) \leq\left(\xi_{i i}\left(\mathbf{x}^{A}\right)\right)^{-1} \\
\left|\begin{array}{cc}
\frac{\partial^{2} v_{i}\left(\mathbf{x}^{A}, \overline{\mathbf{x}}^{B}\right)}{\partial x_{i}^{A} \partial x_{i}^{A}} & \frac{\partial^{2} v_{i}\left(\mathbf{x}^{A}, \overline{\mathbf{x}}^{B}\right)}{\partial x_{i}^{A} x_{j}^{A}} \\
\frac{\partial^{2} v_{i}\left(\mathbf{x}^{A}, \overline{\mathbf{x}}^{B}\right)}{\partial x_{j}^{A} \partial x_{i}^{A}} & \frac{\partial^{2} v_{i}\left(\mathbf{x}^{A}, \overline{\mathbf{x}}^{B}\right)}{\partial x_{j}^{A} \partial x_{j}^{A}}
\end{array}\right| \geq 0 \Longleftrightarrow \kappa_{i}\left(\mathbf{x}^{A}\right) \leq\left(\xi_{i i}\left(\mathbf{x}^{A}\right)+\xi_{i j}\left(\mathbf{x}^{A}\right)\right)^{-1}, i \neq j \\
\left|H_{i}\left(\mathbf{x}^{A}\right)\right| \leq 0 \Longleftrightarrow \kappa_{i}\left(\mathbf{x}^{A}\right) \leq\left(\sum_{j \in N} \xi_{i j}\left(\mathbf{x}^{A}\right)\right)^{-1} .
\end{gathered}
$$

Thus, since $\left(\sum_{j \in N} \xi_{i j}\left(\mathbf{x}^{A}\right)\right)^{-1}<\left(\xi_{i i}\left(\mathbf{x}^{A}\right)+\xi_{i j}\left(\mathbf{x}^{A}\right)\right)^{-1}<\left(\xi_{i i}\left(\mathbf{x}^{A}\right)\right)^{-1}$, condition $\mathbb{C}_{1}$ guarantees that each $v_{i}^{A}\left(\cdot, \overline{\mathbf{x}}^{B}\right)$ is concave on $X$.

Finally, we use condition $\mathbb{C}_{2}$, and we show that the concavity of $v^{A}\left(\cdot, \overline{\mathbf{x}}^{B}\right)$ proved above is preserved under the increasing transformation $\Phi$, establishing the desired result that the power share function $\rho^{A}\left(\cdot, \overline{\mathbf{x}}^{B}\right)$ is also concave on $X$. To do that, recall that by definition, for each $\mathbf{x}^{A} \in X$, $\frac{\partial^{2} \rho^{A}\left(\mathbf{x}^{A}, \overline{\mathbf{x}}^{B}\right)}{\partial x_{i} \partial x_{j}}=\Phi^{\prime \prime}\left(v^{A}\left(\mathbf{x}^{A}, \overline{\mathbf{x}}^{B}\right)\right) \frac{\partial v^{A}\left(\mathbf{x}^{A}, \overline{\mathbf{x}}^{B}\right)}{\partial x_{i}} \frac{\partial v^{A}\left(\mathbf{x}^{A}, \overline{\mathbf{x}}^{B}\right)}{\partial x_{j}}+\Phi^{\prime}\left(v^{A}\left(\mathbf{x}^{A}, \overline{\mathbf{x}}^{B}\right)\right) \frac{\partial^{2} v^{A}\left(\mathbf{x}^{A}, \overline{\mathbf{x}}^{B}\right)}{\partial x_{i} \partial x_{j}}$, which can be rewritten using the notation of Sect. 3 as $\frac{\partial^{2} \rho^{A}\left(\mathbf{x}^{A}, \overline{\mathbf{x}}^{B}\right)}{\partial x_{i} \partial x_{j}}=\frac{\partial v^{A}\left(\mathbf{x}^{A}, \overline{\mathbf{x}}^{B}\right)}{\partial x_{i}} \frac{\partial v^{A}\left(\mathbf{x}^{A}, \overline{\mathbf{x}}^{B}\right)}{\partial x_{j}} \Phi^{\prime}\left(v^{A}\left(\mathbf{x}^{A}, \overline{\mathbf{x}}^{B}\right)\right)\left(\delta\left(v^{A}\left(\mathbf{x}^{A}, \overline{\mathbf{x}}^{B}\right)\right)+\delta_{i j}\left(\mathbf{x}^{A}, \overline{\mathbf{x}}^{B}\right)\right) . \quad$ Therefore, given that $\Phi^{\prime}>0$, it follows that

$$
\begin{aligned}
& \frac{\partial^{2} \rho^{A}\left(\mathbf{x}^{A}, \overline{\mathbf{x}}^{B}\right)}{\partial x_{i}^{A} \partial x_{i}^{A}} \leq 0 \Longleftrightarrow \delta\left(\mathbf{x}^{A}\right) \leq-\Delta^{1}\left(\mathbf{x}^{A}\right) \\
& \left|\begin{array}{ll}
\frac{\partial^{2} \rho^{A}\left(\mathbf{x}^{A}, \overline{\mathbf{x}}^{B}\right)}{\partial x_{i}^{A} \partial x_{i}^{A}} & \frac{\partial^{2} \rho^{A}\left(\mathbf{x}^{A}, \overline{\mathbf{x}}^{B}\right)}{\partial x_{i}^{A} \partial x_{j}^{A}} \\
\frac{\partial^{2} \rho^{A}\left(\mathbf{x}^{A}, \overline{\mathbf{x}}^{B}\right)}{\partial x_{j}^{A} \partial x_{i}^{A}} & \frac{\partial^{2} \rho^{A}\left(\mathbf{x}^{A}, \overline{\mathbf{x}}^{B}\right)}{\partial x_{j}^{A} \partial x_{j}^{A}}
\end{array}\right| \geq 0 \Longleftrightarrow \Delta_{\left[1, \delta\left(\mathbf{x}^{A}\right)\right]}^{2}+\Delta_{\left[2, \delta\left(\mathbf{x}^{A}\right)\right]}^{2} \geq-\Delta^{2}\left(\mathbf{x}^{A}\right) \\
& \left|H_{\rho^{A}}\left(\mathbf{x}^{A}\right)\right| \leq 0 \Longleftrightarrow \sum_{j \leq 3} \Delta_{\left[j, \delta\left(\mathbf{x}^{A}\right)\right]}^{3}\left(\mathbf{x}^{A}\right) \leq-\Delta^{3}\left(\mathbf{x}^{A}\right),
\end{aligned}
$$

which results by applying condition $\mathbb{C}_{2}$ in the Hessian matrix of $\rho^{A}\left(\cdot, \overline{\mathbf{x}}^{B}\right)$ to be negative semi-definite on $X$.

Proof of Proporsition 2 First, notice that equilibrium symmetry (i.e., $\mathbf{x}^{A}=\mathbf{x}^{B}$ ) follows from the fact that, given the policy of the other party, both political organizations face the same optimization problem, namely, 


$$
\begin{gathered}
\max _{\mathbf{x}^{C}} \Pi^{C}\left(\mathbf{x}^{A}, \mathbf{x}^{B}\right) \\
\text { s.t. } \sum_{i \in N} n_{i} x_{i}^{C}=0, \\
x_{i}^{C}+e_{i} \geq 0 \text { for all } i \in N, \\
e_{R}+x_{R}^{C} \geq e_{M}+x_{M}^{C}, \\
e_{M}+x_{M}^{C} \geq e_{P}+x_{P}^{C}, \\
\mathbf{x}^{-C} \text { given } .
\end{gathered}
$$

Without loss of generality, consider next party $A$ 's problem. The Lagrange function is $\mathcal{L}=\Pi^{A}\left(\mathbf{x}^{A}, \mathbf{x}^{B}\right)+\lambda\left[0-\sum_{i \in N} n_{i} x_{i}^{A}\right]+\sum_{i \in N} \mu_{i}\left(x_{i}^{A}+e_{i}\right)+\psi_{1}\left(e_{R}+x_{R}^{A}-e_{M}-x_{M}^{A}\right)$ $+\psi_{2}\left(e_{M}+x_{M}^{A}-e_{P}-x_{P}^{A}\right)$, where $\lambda, \mu_{i}, \psi_{1}$ and $\psi_{2}$ are the multipliers associated with the constraints listed in (5)-(8). Consider first the case where $\lambda>0, \mu_{i}=0$ for all $i \in N, \psi_{1}>0$, and $\psi_{2}=0$. Under this configuration of values of the Lagrange multipliers, the system of first-order conditions reduces to (6) and (8) together with the following equations:

$$
\begin{gathered}
\frac{\partial \Pi^{A}}{\partial x_{R}^{A}}-\lambda n_{R}+\psi_{1}=0, \\
\frac{\partial \Pi^{A}}{\partial x_{M}^{A}}-\lambda n_{M}-\psi_{1}=0, \\
\frac{\partial \Pi^{A}}{\partial x_{P}^{A}}-\lambda n_{P}=0, \\
\sum_{i \in N} n_{i} x_{i}^{A}=0, \\
e_{R}+x_{R}^{A}-e_{M}-x_{M}^{A}=0 .
\end{gathered}
$$

Moreover, since $\mathbf{x}^{A}=\mathbf{x}^{B}$, the vote share of party $A$ is $1 / 2$, implying that

$$
\frac{\partial \Pi^{A}\left(\mathbf{x}^{A}, \mathbf{x}^{B}\right)}{\partial x_{i}^{A}}=(1-\gamma) \eta \frac{\partial v^{A}\left(\mathbf{x}^{A}, \mathbf{x}^{B}\right)}{\partial x_{i}^{A}}-\gamma n_{i}\left(\tilde{e}_{i}+x_{i}^{A}\right),
$$

where $\tilde{e}_{i}=e_{i}-e$ and $\frac{\partial v^{A}\left(\mathbf{x}^{A}, \mathbf{x}^{B}\right)}{\partial x_{i}^{A}}=n_{i} \phi_{i}-2 n_{i}\left(\tilde{e}_{i}+x_{i}^{A}\right) \alpha_{\phi}$. Adding (9) and (10), we have that $\frac{\partial \Pi^{A}}{\partial x_{R}^{A}}+\frac{\partial \Pi^{A}}{\partial x_{M}^{A}}-\lambda n_{R}-\lambda n_{M}=0$, which implies using (14) that 


$$
\lambda=\frac{n_{M}}{n_{M}+n_{R}}\left[(1-\gamma) \eta \phi_{M}-\left(\tilde{e}_{M}+x_{M}^{A}\right) D\right]+\frac{n_{R}}{n_{M}+n_{R}}\left[(1-\gamma) \eta \phi_{R}-\left(\tilde{e}_{R}+x_{R}^{A}\right) D\right],
$$

where $D=(1-\gamma) \eta 2 \alpha_{\phi}+\gamma$. Notice that from (11) and (14), it also follows that

$$
\lambda=(1-\gamma) \eta \phi_{P}-\left(\tilde{e}_{P}+x_{P}^{A}\right) D
$$

Combining (15) and (16) together with (13),

$$
x_{P}^{A}=\frac{(1-\gamma) \eta}{D} \frac{\phi_{P}-\phi}{n_{R}+n_{M}}+e_{M}+x_{M}^{A}-e_{P} .
$$

Substituting (13) and (17) into (12), we get the transfer to the middle class, namely, $x_{M}^{A}=e-e_{M}+\beta_{M}\left(\phi-\phi_{P}\right)$, where $\beta_{M}=\frac{(1-\gamma) \eta \sigma_{P}}{(1-\gamma) 2 \eta \alpha_{\phi}+\gamma}$ and $\sigma_{P}=\frac{n_{P}}{1-n_{P}}$. The transfer to the rich and the poor are obtained by replacing $x_{M}^{A}$ into (13) and (17), respectively. Moreover, using (16), we have that $\lambda=(1-\gamma) \eta \phi$, which is strictly positive as required. Finally, it's easy to verify that these critical values of $x_{i}^{A}$ satisfy (6) and (8). Therefore, they constitute the solution of party's $A$ constrained optimization problem. It is left for the reader to check that any other configuration of values of the Lagrange multipliers violates one or more of the first-order conditions.

Proof of Corollary 1 Without loss of generality, we show the result for party $A$. Recall that $A$ maximizes the payoff function $\Pi^{A}=(1-\gamma) \rho^{A}-\gamma \frac{1}{2} \sum_{i \in \mathcal{N}} n_{i}\left(y_{i}^{A}-y^{A}\right)^{2}$ with respect to $\mathbf{x}^{A} \in X$ subject to the constraints listed in $(5,6,7,8)$. The first part of $\Pi^{A}$, i.e., maximizing $(1-\gamma) \rho^{A}$, is equivalent to maximizing $(1-\gamma) \eta \sum_{i \in \mathcal{N}} n_{i} f_{i}(0) u_{i}\left(\mathbf{x}^{A}\right)$, because these two have the same first-order partial derivatives, namely,

$$
(1-\gamma) \eta n_{i} f_{i}(0) u_{i}^{\prime}\left(\mathbf{x}^{A}\right) .
$$

With regard to the second part of party A's payoff function, notice first that the sum of voters' utility functions $\sum_{i \in \mathcal{N}} n_{i} u_{i}$ is

$$
\sum_{i \in \mathcal{N}} n_{i} u_{i}=y-\hat{\alpha}\left[\sum_{i \in \mathcal{N}} n_{i}\left(y_{i}^{A}-y^{A}\right)^{2}\right] \text {, }
$$

where $\hat{\alpha}=\sum_{i \in \mathcal{N}} n_{i} \alpha_{i}$. Thus, maximising $-\gamma \frac{1}{2} \sum_{i \in \mathcal{N}} n_{i}\left(y_{i}^{A}-y^{A}\right)^{2}$ is equivalent to maximising $\gamma \frac{1}{2 \hat{\alpha}} \sum_{i \in \mathcal{N}} n_{i} u_{i}\left(\mathbf{x}^{A}\right)$, which proves the desired result, that is, $\mathbf{x}^{A}=\arg \max _{\mathbf{x} \in X} \sum_{i \in \mathcal{N}}^{2 \hat{\alpha}} d_{i} u_{i}(\mathbf{x})$, with $d_{i}=(1-\gamma) \eta n_{i} f_{i}(0)+\gamma \frac{n_{i}}{2 \sum_{i \in \mathcal{N}} n_{i} \alpha_{i}}$.

\section{Appendix B: Empirical Appendix}

This section displays additional information that complement Sect. 4. More precisely, Table 7 offers details about the observations informing the regressions of the paper; and Tables 8 and 9 collect the results for the net transfers and the Gini, 
Table 7 Number of observations and years by country in the regressions with the full sample

\begin{tabular}{|c|c|c|c|}
\hline Country & Transfers & Gini & Years \\
\hline Australia & 8 & 8 & 19811985198919952001200320082010 \\
\hline Austria & 1 & 6 & 1987(G) 1994(G) 1995(G) 1997(G) 2000(G) 2004 \\
\hline Belgium & 0 & 6 & 1985(G) 1988(G) 1992(G) 1995(G) 1997(G) 2000(G) \\
\hline Canada & 12 & 12 & $\begin{array}{l}19711975198119871991199419971998200020042007 \\
2010\end{array}$ \\
\hline Czech Republic & 5 & 5 & 19962002200420072010 \\
\hline Denmark & 7 & 7 & 1987199219952000200420072010 \\
\hline Estonia & 0 & 4 & $2000(\mathrm{G}) 2004(\mathrm{G}) 2007(\mathrm{G}) 2010(\mathrm{G})$ \\
\hline Finland & 3 & 7 & 1987(G) 1991(G) 1995(G) 2000(G) 200420072010 \\
\hline France & 2 & 7 & 1978(G) 1984(G) 1989(G) 1994(G) 2000(G) 20052010 \\
\hline Germany & 4 & 5 & 1994(G) 2000200420072010 \\
\hline West Germany & 4 & 6 & 1973(G) 1978(G) 1981198319841989 \\
\hline Greece & 3 & 5 & 1995(G) 2000(G) 200420072010 \\
\hline Hungary & 0 & 6 & 1991(G) 1994(G) 1999(G) 2005(G) 2007(G) 2009(G) \\
\hline Ireland & 4 & 8 & 1987 1994(G) 1995(G) 1996(G) 2000(G) 200420072010 \\
\hline Israel & 2 & 0 & 1992(T) 2001(T) \\
\hline Italy & 3 & 11 & $\begin{array}{l}1986(\mathrm{G}) 1987(\mathrm{G}) 1989(\mathrm{G}) 1991(\mathrm{G}) 1993(\mathrm{G}) 1995(\mathrm{G}) 1998(\mathrm{G}) \\
2000(\mathrm{G}) 200420082010\end{array}$ \\
\hline Japan & 1 & 1 & 2008 \\
\hline Netherlands & 4 & 8 & 1983(G) 1987(G) 1990(G) 1993(G) 1999200420072010 \\
\hline Norway & 8 & 8 & 19791986199119952000200420072010 \\
\hline Poland & 5 & 6 & 1992(G) 19951999200420072010 \\
\hline Romania & 0 & 1 & 1997(G) \\
\hline Slovakia & 1 & 4 & 1996(G) 2004(G) 2007(G) 2010 \\
\hline Spain & 3 & 8 & 1980(G) 1985(G) 1990(G) 1995(G) 2000(G) 200420072010 \\
\hline Sweden & 8 & 7 & 1967(T) 1975198119871992199520002005 \\
\hline Switzerland & 5 & 5 & 19821992200020022004 \\
\hline United Kingdom & 11 & 10 & $\begin{array}{l}\text { 1969(T) } 197419791986199119941995199920042007 \\
\quad 2010\end{array}$ \\
\hline United States & 10 & 10 & 1974197919861991199419972000200420072010 \\
\hline Total No Observations & 114 & 171 & \\
\hline
\end{tabular}

$\mathrm{T}(\mathrm{G})$ means that data is present only for the Net Transfers (the Gini)

respectively, coming from the alternative specifications of the econometric models examined in the online appendix. ${ }^{33}$

Besides the baseline model discussed in Sect. 4, to assess the robustness of the results, we consider in the online appendix six alternative models. The first replaces

\footnotetext{
33 Along Tables 8 and 9, a cell with a $\%$ figure indicates the statistical significance with which the hypothesis under analysis is confirmed. A cell with the word 'sign' indicates that the sign of the coefficient validates the hypothesis, but without statistical significance. Finally, a cell with a dash '-' symbol indicates that the sign of the coefficient does not validate the hypothesis under analysis.
} 


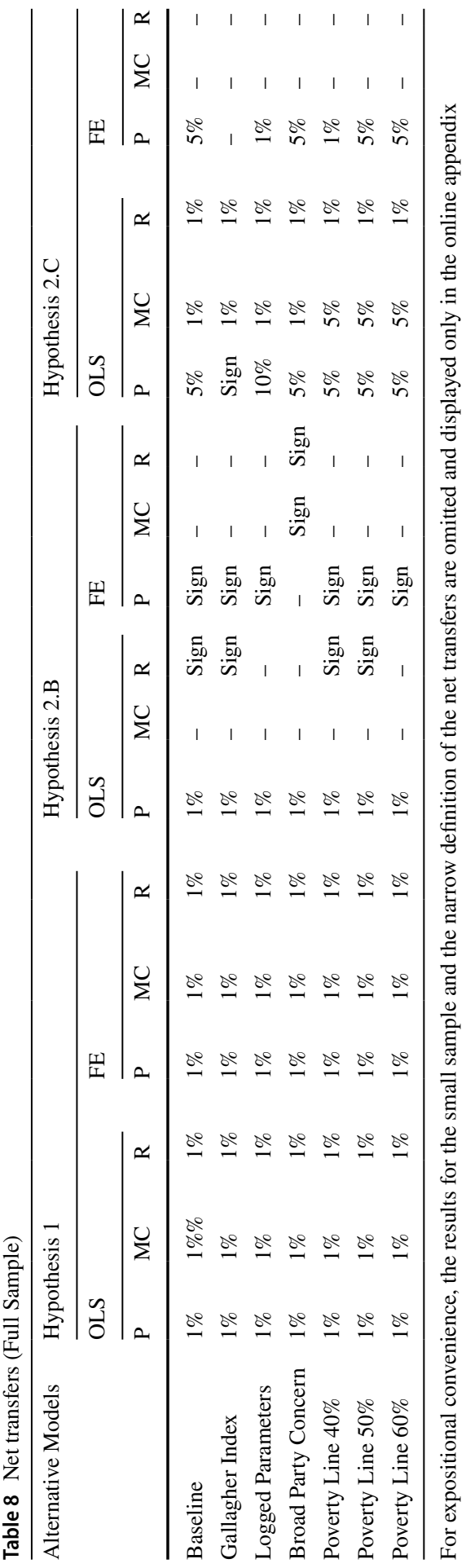




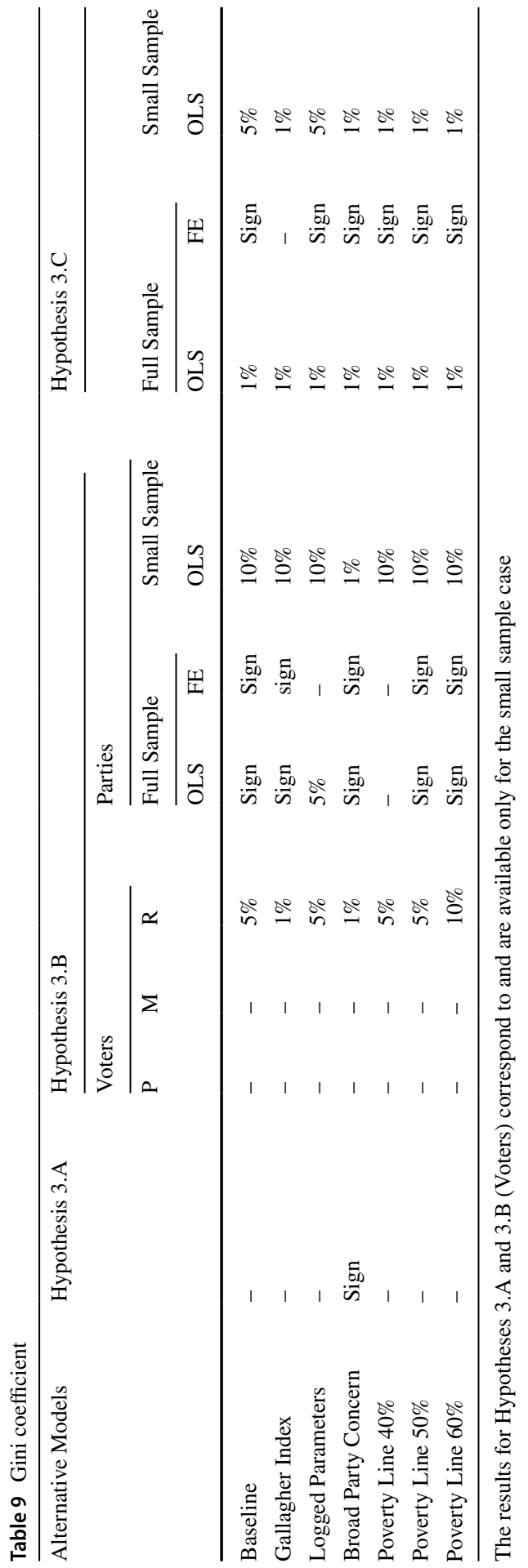


the Taagepera index in the baseline model for another widely used index of the electoral rule disproportionality, called the Gallagher index. The second considers a nonlinear approximation to the relationships under analysis. These regressions take the natural logarithm of the parameters present in the tactical redistribution term, reflecting that some of the parameters in Proporsition 2 affect the equilibrium values in a nonlinear way.

The third model examines a broader definition of the parties' inequality concern, combining with equal weights the one discussed in Sect. 4, that is, MPDS-per503, with MPDS-per504: "Favourable mentions of need to introduce, maintain or expand any public social service or social security scheme". Finally, the fourth, fifth, and sixth model, respectively, consider alternative definitions of the income groups, which results from employing the other risk-of-poverty lines used by EU-SILC, namely, 40, 50, and 60 percent of the median income.

For the sake of conciseness, Tables 8 and 9 only display a general overview of the results obtained in each of these alternative models, including the baseline case of Sect. 4, relegating a more detailed discussion of them to the online appendix.

Supplementary Information The online version of this article (https://doi.org/10.1007/s00355-02101310-5) contains supplementary material, which is available to authorized users.

Open Access This article is licensed under a Creative Commons Attribution 4.0 International License, which permits use, sharing, adaptation, distribution and reproduction in any medium or format, as long as you give appropriate credit to the original author(s) and the source, provide a link to the Creative Commons licence, and indicate if changes were made. The images or other third party material in this article are included in the article's Creative Commons licence, unless indicated otherwise in a credit line to the material. If material is not included in the article's Creative Commons licence and your intended use is not permitted by statutory regulation or exceeds the permitted use, you will need to obtain permission directly from the copyright holder. To view a copy of this licence, visit http://creativecommons.org/licen ses/by/4.0/.

\section{References}

Alesina A, Angeletos G (2005a) Fairness and redistribution: US vs. Europe. Am Econ Rev 95:913-935

Alesina A, Angeletos G (2005b) Redistribution, corruption and fairness. J Monet Econ 5:1227-1244

Alesina A, Giuliano P (2010) Preferences for redistribution. In: Benhabib J, Bisin A, Jackson M (eds) Handbook of social economics 1A. North Holland Publisher, Amsterdam, pp 93-129

Alesina A, Cozzi G, Mantovan N (2012) The evolution of ideology, fairness, and redistribution. Econ J 122(565):1244-1261

Arrow K (1963) Social choice and individual values. Wiley, New York

Arulampalam W, Dasgupta S, Dhillon A, Dutta B (2009) Electoral goals and center-state transfers: a theoretical model and empirical evidence from India. J Dev Econ 88(1):103-119

Cameron C, Miller DL (2015) A practitioner's guide to cluster-robust inference. J Hum Resour 50(2):317-372

Carey J, Hix S (2011) The electoral sweet spot: low-magnitude proportional electoral systems. Am J Polit Sci 55(2):383-397

Corneo G, Gruner PH (2002) Individual preferences for political redistribution. J Public Econ 83:83-107

Cox G (2010) Swing voters, core voters and distributive politics. In: Shapiro I, Stokes S, Wood E, Kirshner A (eds) Political representation. Cambridge University Press, Cambridge, pp 342-57

Cox G, McCubbins M (1986) Electoral politics as a redistributive game. J Polit 48:370-89 
Dawes C, Fowler J, Johnson T, McElreath R, Smirnov O (2007) Egalitarian motives in humans. Nature 446:794-796

Dawes C, Loewen P, Schreiber D, Simmons A, Flagan T, McElreath R, Bokemper S, Fowler J, Paulus M (2012) Neural basis of egalitarian behavior. Proc Natl Acad Sci USA 109(17):6479-6483

Dhami S, Nowaihi A (2010a) Redistributive policy with heterogenous social preferences of voters. Eur Econ Rev 54(6):743-759

Dhami S, Nowaihi A (2010) Existence of a Condorcet winner when voters have other-regarding preferences. J Public Econ Theory 12(5):897-922

Dixit A, Londregan J (1995) Redistributive politics and economic efficiency. Am Polit Sci Rev 89:856-66

Dixit A, Londregan J (1996) The determinants of success of special interests in redistributive politics. J Polit 58:1132-55

Drouvelis M, Saporiti A, Vriend NJ (2014) Political motivations and electoral competition: equilibrium analysis and experimental evidence. Games Econ Behav 83:86-115

Engelmann D, Strobel M (2004) Inequality aversion, efficiency, and maximin preferences in simple distribution experiments. Am Econ Rev 94(4):857-869

Feenstra RC, Inklaar R, Timmer MP (2015) The next generation of the Penn world table. Am Econ Rev 105(10):3150-3182

Fehr E, Schmidt K (1999) A theory of fairness, competition, and cooperation. Q J Econ 114:817-868

Flamand S (2012) Heterogeneous social preferences in a model of voting on redistribution. Unpublished manuscript, Universidad Autónoma de Barcelona, pp 1-26

Franzese R (2010) The multiple effects of multiple policymakers: Veto actors bargaining in common pools. Rivista Italiana di Scienza Politica 40(3):341-70

Fuller M (1979) The estimation of Gini coefficients from grouped data. Econ Lett 3(2):187-192

Funk P, Gathmann C (2013) How do electoral systems affect fiscal policy? Evidence from cantonal parliaments, 1890-2000. J Eur Econ Assoc 11(5):1178-1203

Galasso V (2003) Redistribution and fairness: a note. Eur J Polit Econ 19(4):885-892

Gallagher M (1991) Proportionality, disproportionality and electoral systems. Electrol Stud 10(1):33-51

Herrera H, Morelli M, Nunnari S (2016) Turnout across democracies. Am J Polit Sci 60(3):607-624

Larcinese V, Snyder J, Testa C (2013) Testing models of distributive politics using exit polls to measure voters' preferences and partisanship. Br J Polit Sci 43:845-875

Lijphart A (2012) Patterns of democracy. Government forms and performance in thirty-six countries, 2nd edn. Yale University Press, New Haven

Lindbeck A, Weibull J (1987) Balanced-budget redistribution as the outcome of political competition. Public Choice 52(3):273-297

Lizzeri A, Persico N (2001) The provision of public goods under alternative electoral incentives. Am Econ Rev 91:225-245

Luttens R, Valfort M (2012) Voting for redistribution under desert-sensitive altruism. Scand J Econ 114(3):881-907

Matakos K, Troumpounis O, Xefteris D (2015) Electoral rule disproportionality and platform polarization. Am J Polit Sci. https://doi.org/10.1111/ajps.12235

Meltzer AH, Richard SF (1981) A rational theory of the size of government. J Polit Econ 89:914-927

Milesi-Ferretti G-M, Perotti R, Rostagno M (2002) Electoral systems and the composition of public spending. Q J Econ 117:609-657

Moser R, Scheiner E (2004) Mixed electoral systems and electoral system effects: controlled comparison and cross-national analysis. Electoral Stud 23(4):575-599

Persson T, Tabellini G (1999) The size and scope of government: comparative politics with rational politicians. Eur Econ Rev 43:699-735

Persson T, Tabellini G (2000) Political economics: explaining economic policy. MIT Press, Cambridge

Powell G (2000) Elections as instruments of democracy: majoritarian and proportional visions. Yale University Press, New Haven

Saporiti A (2014) Power sharing and electoral equilibrium. Econ Theory 55(3):705-729

Taagepera R (1986) Reformulating the cube law for proportional representation elections. Am Polit Sci Rev 80:489-504

Theil H (1969) The desired political entropy. Am Polit Sci Rev 63:521-525

Tyran J-R, Sausgruber R (2006) A little fairness may induce a lot of redistribution in democracy. Eur Econ Rev 50(2):469-485

Volkens A, Lehman P, Matthieß T, Merz N, Regel S, Weßels B (2015) The Manifesto Data Collection. Manifesto Project (MRG/CMP/MARPOR). Version 2015a. Berlin: Wissenschaftszentrum Berlin für Sozialforschung (WZB)

Publisher's Note Springer Nature remains neutral with regard to jurisdictional claims in published maps and institutional affiliations. 